\title{
"Planning and Design Indicators for Hospitals of Blood Diseases and Tumors in Iraq"
}

\author{
Zainab Ali Abdulwaheed Bahjat Rashsd Shahin
}

Architecture Engineering department, University of Baghdad, Baghdad, Iraq

zainab.mandool@yahoo.com_bahjatsha@yahoo.com

\begin{tabular}{|l|l|l|}
\hline Submission date:- 3/3/2019 & Acceptance date:- 3/4/2019 & Publication date:-9/5/2019 \\
\hline
\end{tabular}

\begin{abstract}
The hospitals of blood diseases and tumors are among the most important specialized hospitals, which aim to improve the health situation in general and patients with blood and tumors in particular through the provision of a comprehensive hospital for tumors, radiotherapy and chemical as well as guidance services and social awareness, and although most of the local hospitals are within the minimum standards of global standards, but they do not meet local privacy, which requires the development of design indicators and are in line with local reality.

The problem of research has become "limited local studies that dealt with the planning and design indicators of the space dimensions of the hospitals of blood diseases and tumors rules and mechanisms of work in terms of functional, environmental, structural, social and precautionary"

In light of the research problem, the research goal was to "identify comprehensive indicators in the light of advanced global experiences as a measure of all the components and indicators of planning and design systems for hospital buildings of blood diseases and tumors".

To extract the vocabulary of the theoretical framework and apply it to the selected research sample, and then to present the orthographic results of the design and planning of hospitals of blood diseases and local tumors.
\end{abstract}

Keywords: Radiation therapy, Chemotherapy, Psychological and Social awareness within the space dimension in the medical institution. 


\section{"المؤشرات التخطيطية والتصميمية لمستثفيات امراض الام والاورام في العراق" بهجت رشاد شاهين \\ زينب علي عبد الواحد مندول \\ قسم هندسة العمارة، جامعة بغد/د، بغد/د، العر/ق \\ bahjatsha@yahoo.com zainab.mandool@yahoo.com}

الخلاصة

تعد مستثفيات امر اض الدم الاور ام من اهم المستثفيات المتخصصة حيث تهدف الى الارتقاء بالوضع الصحي عامة ومرضى فئ

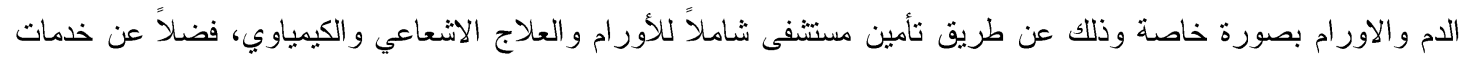

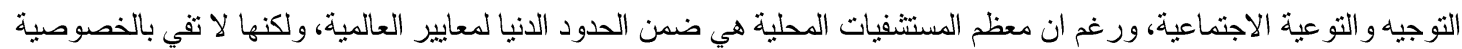
المحلية، مما ينظلب ايجاد مؤشر ات تصميمية لها وتتمانشى مع الو اقع المحلي.

لتصبح مشكلة البحث "محدودية الدراسات الدحـلية التـي تــــاولت المؤشرات التـخطيطية و التصميمية للأبعاد الفضائية لمسـتشفيات امر اض الدم والاورام وقو اعد واليات عملها من حيث الجواتب الوظيفية و البيئية والآثائية والاجتماعية " وفي ضوء المشكلة البحثية حدد الهدف البحثي وهو" تحديد مؤشرات شاملة في ضوء التجارب العالمية المتقدمة كمسطرة

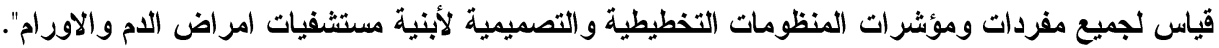
وصو لاً الى استخلاص مفردات الإطار النظري وتطيقها على العينة البحثية المنتخبة، ثم عرض النتائج الثتويمية الخاصة بتصميم وتخطيط مستثفيات امر اض الدم و الاورام المحلية. الكلمات الدالة: العلاج الاشعاعي، العلاج الكيميائي، التو عية النفسية والاجتماعية ضمن البعد الفضائي في المؤسسة الطبية.

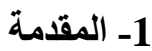

يتولى قطاع الرعاية الصحية مسؤولية انتاج مجتمع صحي قادر على اداء واجبه في العمل و اكتساب العلم والمعرفة لمو اكبة

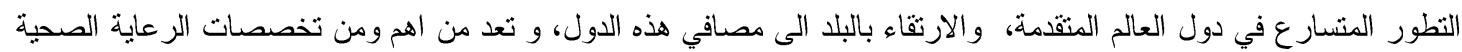

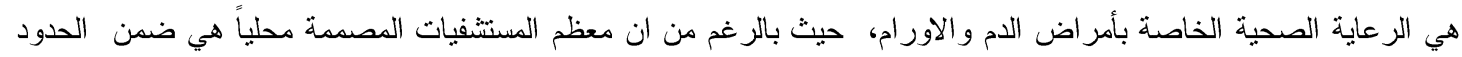

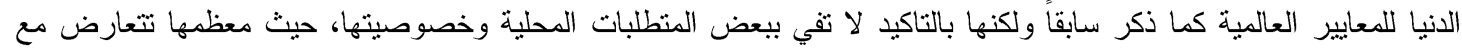

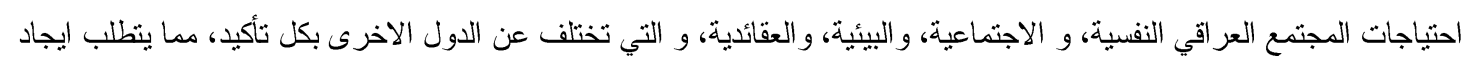
مؤشر ات تصميمية و تخطيطية تثماثىى مع الو اقع المحلي فضلا عن التز امها بجميع مؤشرات الحماية الييئية خارجياً و داخلياً، وتكامل مو اقعها التثخيصبة و العلاجية والايو ائية . . و اعتد الباحث في استخلاص مثكلت البحثية و اهدافها عن طريق اجر اء استعر اض موسع للتجربة العالمبة والعربية، ودراسة

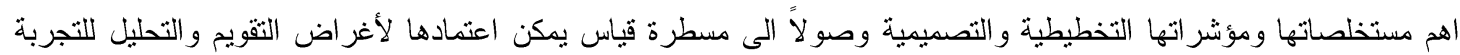

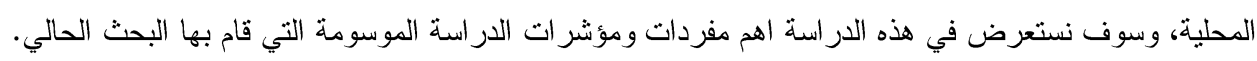

\section{2- مفهوم المستثفيات المتخصصة بامر اض الام و الاورام:}

ان تعريف المستشفى طبقاً للموسو عة البريطانية المختصرة (Britannica) 1 هي مؤسسة لتشخيص وعلاج المرضى او

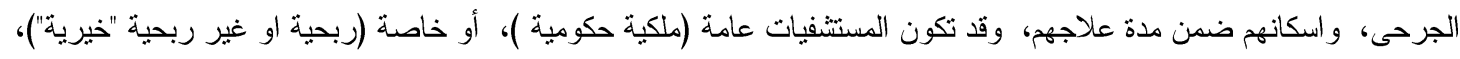

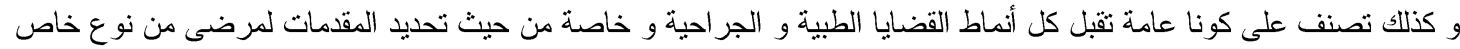

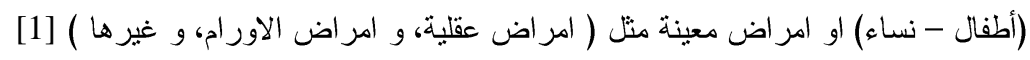

وهي الموسو عة البريطانية و ي نسخة الكترونية موجودة ضمن شبكة الانترنت تتحدث بأستمرار:Britannica online 
اما مستشفيات الاور ام تعد من المستثفيات المتخصصة جداً والتي تعتمد على الرعاية الطبية المتطورة والجراحية الجيدة فيها فضلا عن توفر الخدمات الطيية الاشعاعية التتخيصية الفورية وذلك عن طريق تقنيات الاجهزة الطبية الاشعاعية الحديثة اللازمة في مجال التشخيص و العلاج الفعال والاشعة السينية الحيوية، حيث يحتاج العلاج الاشعاعي في هذه المستشفيات الى تكنولوجيا متقدمة

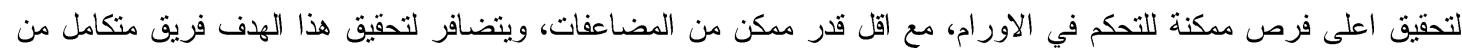

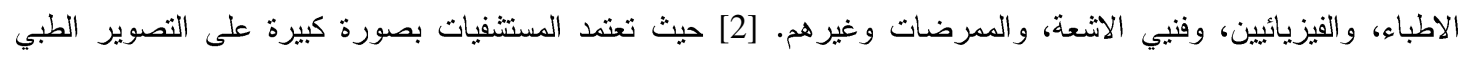
و هو احد فروع الطب الحديث فهو اساسي ولا غنى عنه للتنخيص حيث ينم اختيار نوع العلاج المناسب (medical imaging)

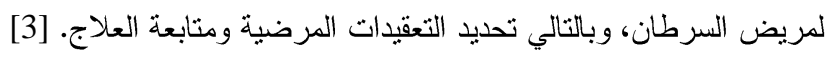
3-الواقع الصحي لمستثفيات امراض الدم و الاورام في العراق:

ان الو اقع الصحي لمستثفيات امر اض الدم والاور ام ضعيف جدا، حيث قبل العام (2008) لم يكن هناك مستثفيات متخصصة

بالاورام عدا عدد محدود من المستشفيات القديمة مثل (مستثفى الامل) في بغداد التي تم انثاؤها في العام ( 1968) وقد الصبح و اقعها الطبي بمرور الزمن لا يو اكب التطور ات التكنولوجيا، فبالتالي لا يلبي احتياجات مرضى السرطان في البلد، وفي مدينة الطب حتى العام (2008) لم يكن فيها مستتفى تخصصي في الامر اض السرطانية، وكانت المستثفيات العامة هي التي تقوم باستقبال

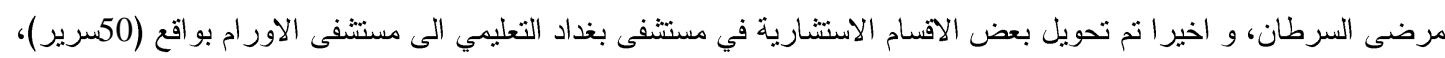
وفي العام (2007) تم انثاء مستثفى اور ام في مدينة الطب تحتوي فقط على العلاج الكيمباوي، وفي العام (2015) تم انشاء مركز بغداد للاشعاع الذي يحتوي (المعجل الخطي) وهو العلاج الخاص بالاشعاع، وفي الوقت نفسه نم اعادة تأهيل مسنتفى الامل

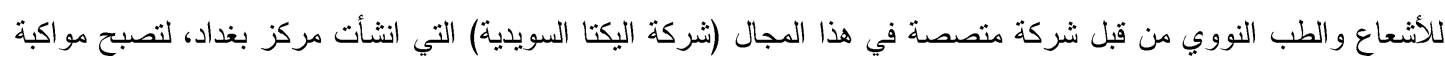

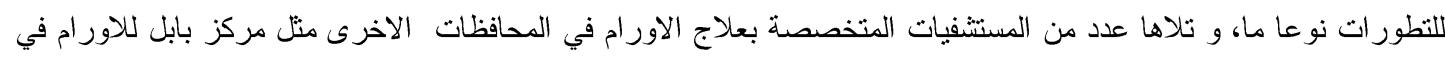

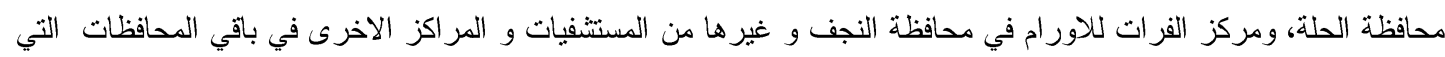

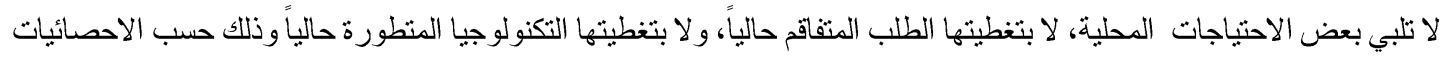

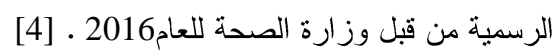

\section{4-المؤشر ات التخطيةية للمستثفيات التخصصية و التي في مقدمتها مستثفيات الاورام:}

تثير المعايير العالمية لتخطيط مو اقع الخدمات الصحية ومن ضمنها المستثفيات التخصصية على ان تمتاز مو اقعها بالهدوء،

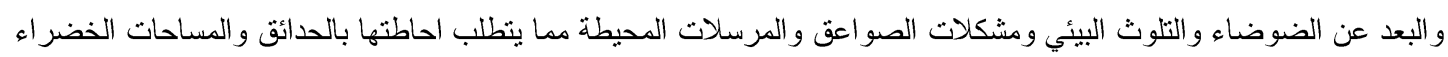
و بعيدا عن المجاورة السكنية او مجموعه المجاور ات الاسكانية في المدينة او على مستوى الاقليم والدولة، وقد تتصاعد مستويات الخدمة في المستشفيات التخصصية لامر اض السرطان لكي تخدم شريحة اكبر على مستوى الاقليم وقد تظهر بعض الاستعمالات

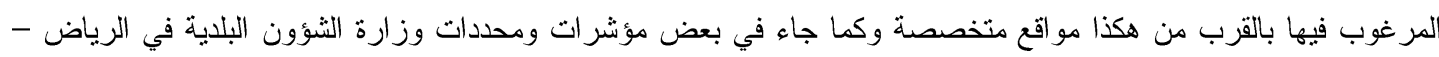

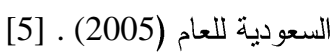

وكما موضحة في الجدول (1) وهو يعد كمثال لبعض البلدان العربية .

\begin{tabular}{|c|c|}
\hline \multicolumn{2}{|c|}{ 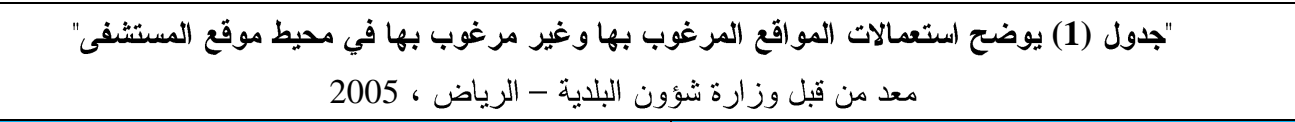 } \\
\hline مو اقع مجاورة مرغوب فيها & مواقع مجاورة غير مرغوب فيها \\
\hline الحدائق و المسطحات المائية & 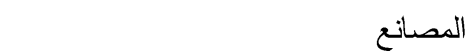 \\
\hline المناطق المفتوحة و الهادئة لتعظيم حب الطبيعة (البايوفيليا) & 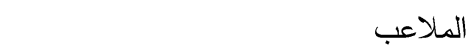 \\
\hline البيئة الطبيعية & البرك و مسطحات تتقية الصرف الصحي \\
\hline قرى سياحية ذات استقلالية عن الموقع الاساس & تقاطعات الطرق الرئيسة \\
\hline تجمعات سكنية مستفيدة & المقابر \\
\hline 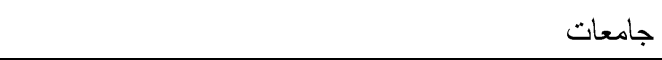 & 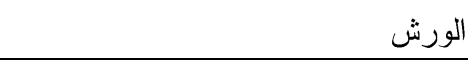 \\
\hline نو ادي صحية للتأهيل النفسي للمرضى بعد العلاج & الاسو اق و التجمعات السكانية \\
\hline
\end{tabular}


رغم ان هذه المحددات المشار اليها في الجدول (1) تأخذ طابعاً عاماً في ترصين مواقع المستشفيات، الا انها قد تخضع الى مؤشرات اكثر صرامة ودقة في حالة اذا كان المسنثفى متخصصاً في امراض الدم والاورام، وله صفة التلويث البيئي من

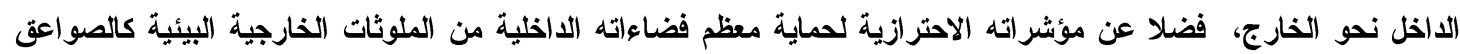

ونشير هنا الى المؤشرات التخطيطية التي تؤثر على مستشفيات امر اض الدم والاورام داخل البيئة الحضرية:

اولا-اسنقلالية الموقع : حيث تتضمن خصوصيات توقيع الموقع ضمن حدود تضمن استقلاليته عن المجاورات، بحيث يعمل على خدمة المناطق المجاورة لكن في الوقت نفسه يمناز بالاستقلالية عنها لهنع التلوث وسهولة الوصول اليه، ولعموم المستشفيات

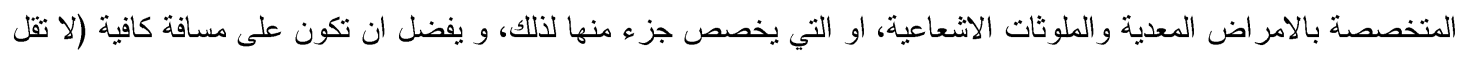

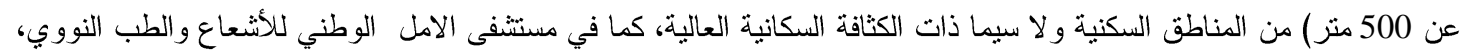
و التي يجب توقيعها بشكل صحيح بحيث لا تؤثز على المباني المحيطة بسبب التأثير الاشعاعي لها.

ثانيا- سهولة الوصول الى الموقع : ونتشمل سهولة الوصول الى الموقع عن طريق ضمان تسقيط موقعه على عدة طرق رئيسة

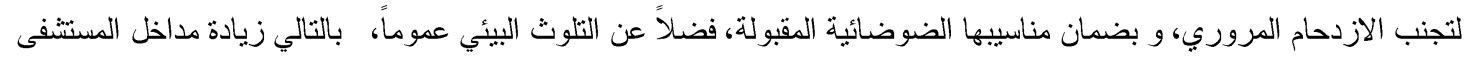
لكي تخدم اكبر عدد من المرضى حسب التخصصات المختلطة لذا يفضل تعدد الطرق الموصلة للمستشفى وذلك لتجنب الازدحام امام المداخل المختلة و على أن يكون الموقع على اتصال بشبكات الطرق الرئيسة ومحطات المواصلات العامة التي تعمل داخل

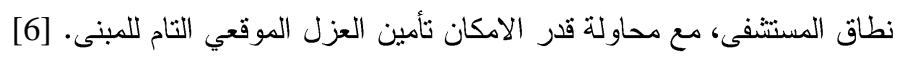

ثالثا-مركزيته نسبة الى المواقع المخدمة : يضمن هذا المؤشر تحقيق توقيع المستشفى على مسافة متقاربة من المناطق المجاورة،

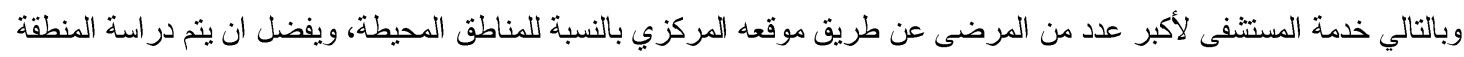

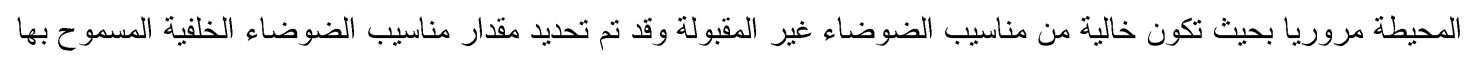
حول المستشفيات بمتوسط (20-35) ديسيبل، وقد يسمح بمنسوب صوتي يصل الى ( 50) ديسيبل في بعض الاقسام حتى ينت

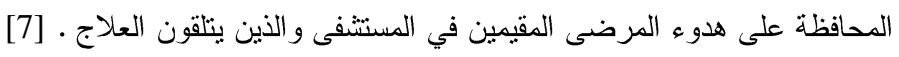

رابعا- توفير سكن للأطباء و للمر افقين: يفضل نوفير تجمعات سكنية ملحقة بالمستشفى لتوفير سكن للأطباء فضلا عن سكن للمر افقين

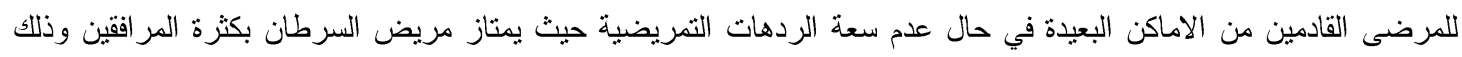

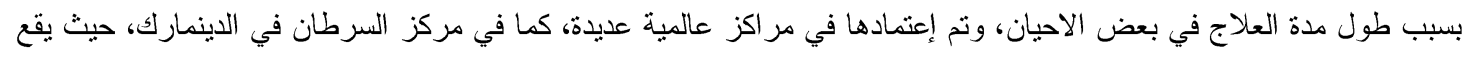

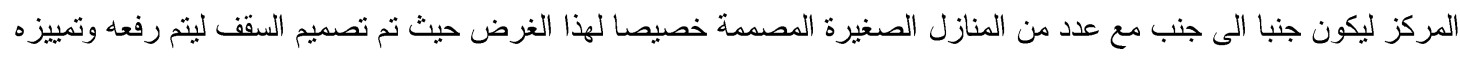
على شكل ورقة الاوريغامي، علما ان المركز يقع بالقرب من مركز الرعاية الصحية في وسط المدينة ضمن النسيج الحضري حيث

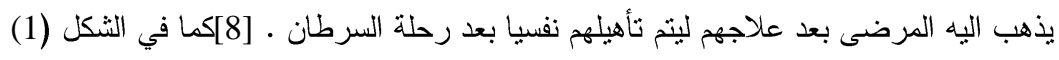

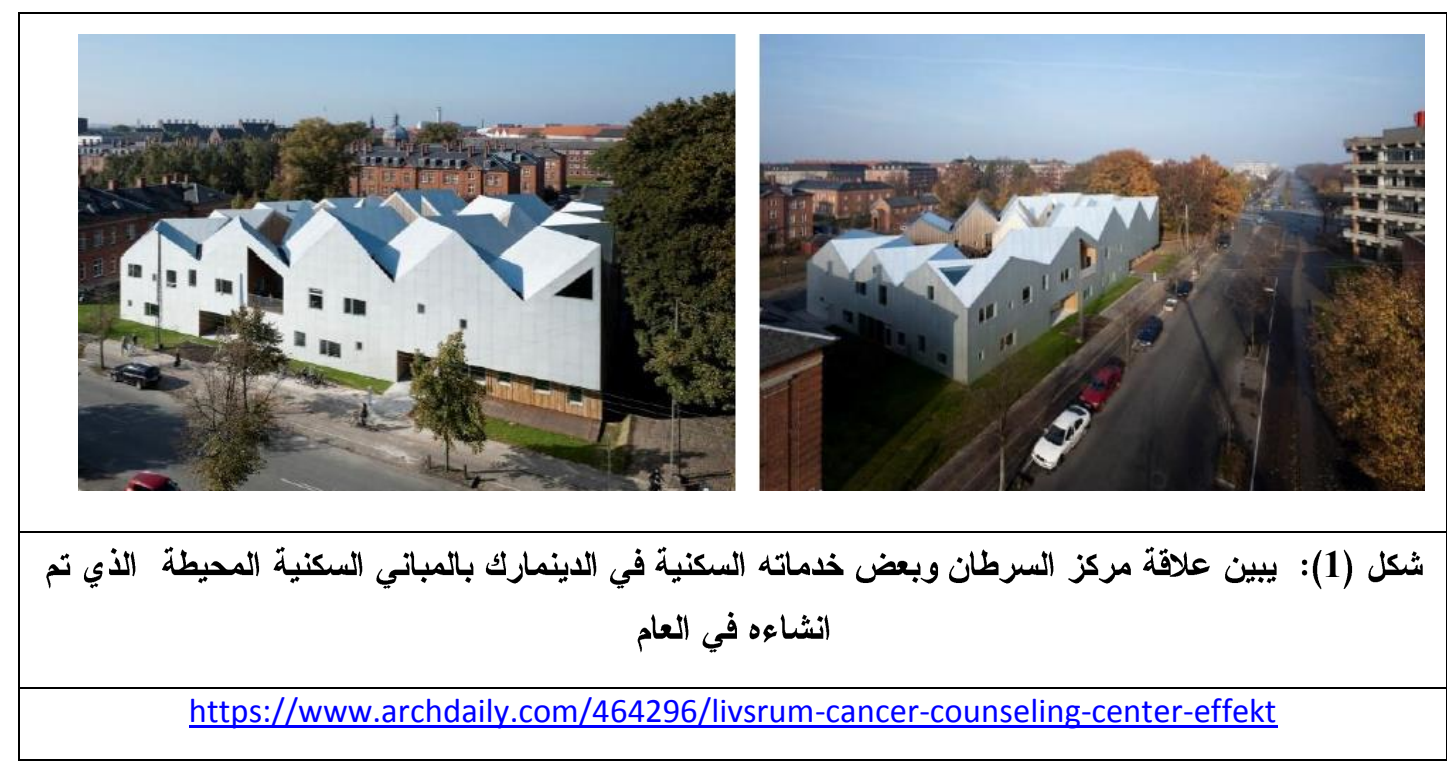


خامسا-امكانية التوسيع المستقبلي: يضمن هذا المؤشر وجود مواقع خالية قريبة وكافية تابعة لموقع المسنتفى لتحقيق التوسيع المستقبلي على مستوى المستشفى و على مستوى الاقسام، وان الاملاء الحضري للمدينة يحدد بشكل كبير التوسيع المستقبلي للمسنتفى. سادسا-توجيه اقسام المستثفى نحو البيئة الخارجية : توجيه مبنى المستثفى تتحكم به كلاً من الثمس واحمالها الحرارية و الضوئية و الرياح في توجيه المستشفى، وعادة يوجه مبنى المستشفى باتجاه الرياح السائدة وذات الأثر الجيد، في حين يكون المبنى موازيًا

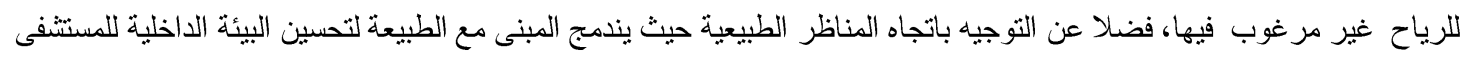
وتلطيف نفسية المريض عن طريق تتظيم مؤشر حب الطبيعة (البايوفيليا)، كما في الثنكل (2) الذي يبين انفتاح على الطبيعة في مركز

بالارت العلاجي في استر اليا، والافادة من ضوء الثمس واحمالها الحرارية شتاءٌ في عملية العلاج و واعادة التأهيل النفسي. [9]
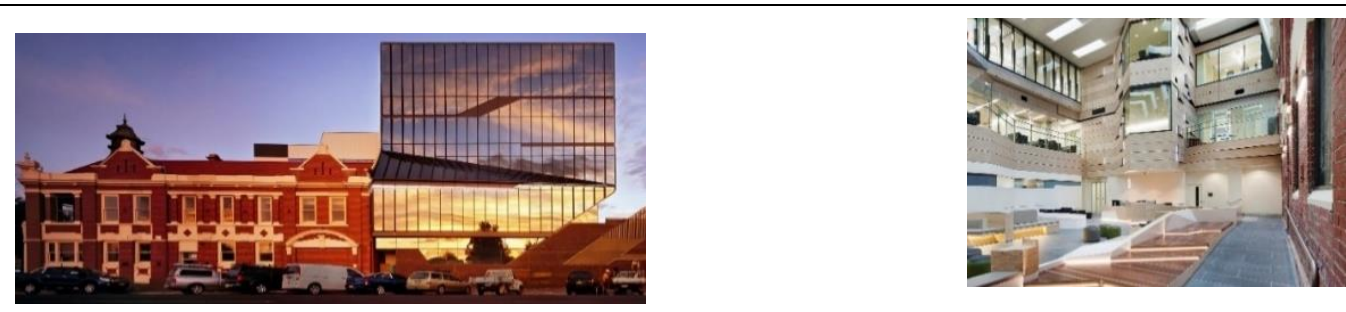

شكل (2): يبين انفتاح و اندماج مركز السرطان في استر اليا مع البيئة المحيطة لتنظيم مؤشر البايوفيليا وملانمته معها

https://www.archdaily.com/ballarat-regional-integrated-cancer-centre-billard-leecepartnership

سابعا-كفاية مداخل المشروع: يضمن هذا المؤشر وضع عدة مداخل للمركز، بحيث تكون كافية للمرضى والمر افقين، والملاك الطبي، و الفني و الخدمات الهندسية و اللوجستية ضمن الاقسام المختلفة.

ثامنا- كفاية مو اقف السيارات داخل الموقع: يضمن هذا المؤشر توفير كاف لمو اقف السيار ات الخاصة بالمتو اجدين و المستخدمين للمستتفى، حيث تكون كافية للمرضى، ومر افقيه،، و الملاك الطبي و الفني، والخدمات الهندسية و اللوجستية، وعادة تختلف معايير

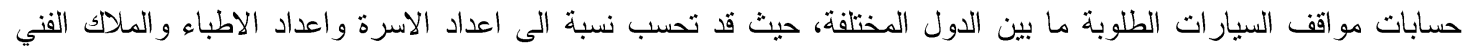
وبتقدير ات مختلفة، علما ان المعايير المحلية لا تنطرق بوضوح الى هكذا مو اقع متخصصة، وتعتمد على اجتهادات المصمم. [10]

\section{5-الاقسام المحتملة لمستشفيات امر اض الام و الاور ام:}

ان تصميم مستتفى امر اض الدم والاور ام يتكون من عدة اقسام، مماتلة لأقسام المستتفى الاخرى، لكن تحتوي على اقسام

اضافية كقسم العلاج الاشعاعي، وقسم العلاج الكيمبائي، وقسم الطب النووي، وقسم العلاج الطبيعي لمرضى السرطان، التي تميزها عن غير ها من المستتفيات، وستؤثر اقسام المستثفى لرعاية الخدمة على مكونات التخطيط الوظيفي وتتطيقه العام، وسوف يعتمد دور تعبين النماذج التشغيلية في المستشفى على نوع ومدى كفاءة منطلبات خدمات الاورام. حيث ان الاقسام الرئيسة داخل المستشفى

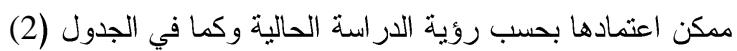

جدول(2 ) : يمثل التنطيق الآموذجي لأقسام مستثفيات امراض الام والاورام اعداد (الباحثان)- بأستخلاص عن التجارب العالمية في هذا المجال وعادة بترك المجال امام المختصين بالاضافة او الحذف وحسب خصوصية المشروع المعني

\begin{tabular}{|c|c|c|}
\hline الملاحظات & القسم & ت \\
\hline تشمل وحدة الادخال و السجلات الطبية ومو اقع الانتظار و السيطرة & المدخل الرئيس للمستشفى & او لا \\
\hline تشمل الإدارة و الارشيف المركزي و الاتصالات & القسم الإداري و السيطرة النوعية & ثثانيا \\
\hline قالطم التشخيص الاشعاعي و الوحدات الاشعاعية والذي يرنبط مع & العيادة الخارجية و التشخيص الاشعاعي & ثالثا \\
\hline
\end{tabular}


Journal of University of Babylon for Engineering Sciences, Vol. (27), No. (2): 2019.

\begin{tabular}{|c|c|c|}
\hline المختبر ات مع كافة الفضاءات الساندة لها & المختبر ات التشخيصية المركزية & ر كابعا \\
\hline خاص بالعلاج الاشعاعي و الوحدات الاشعاعية و الكيمياوي و الفيزياوية & النطاق العلاجي & خامسا \\
\hline الذي يشمل خدمات الطب النووي و الفيزياء الطبية & قسم الطب النووي & سادسا \\
\hline مع ردهة الانتظار اليومي والحجز & وحدة الطوارئ والاسعاف الفوري & سابعا \\
\hline صالات عمليات رئيسة + صالة عمليات ملوثة & قسم العمليات الجر احية & ثنامنا \\
\hline عناية مركزة ملوثة و عناية مركزة عامة & وحدة العناية المركزة & ت تاسعا \\
\hline خاصة بحالات المرضى عديمة الثفاء & وحدة الألم السريري & عاشر \\
\hline (وحدة التمريض العامة- +وحدات التمريض الخاصة بامر اض الام & الاجنحة التمريضية & عشر احدى \\
\hline تشمل التعقيم المركزي و المذخر و المخازن المركزية وبيث الميث & التجهيزات العامة و اللوجستية & عشر \\
\hline 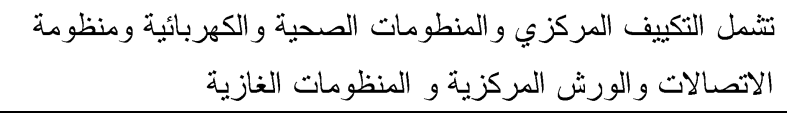 & الخدمات الهندسية & ثناثة \\
\hline
\end{tabular}

6-المؤشرات التصميمية لأهم الأقسام التخصصية لمستثفيات امراض الدم و الاورام:

تطورت في الاونة الاخيرة معالجة مرض السرطان بالجر احة، وبالعلاج الكيمياوي أو بالعلاج الإشعاعي، وتطور أيضا العلاج الدناعي و العلاج بأضداد وحيد النسلية والعلاج بالتجميد وعلاجات أخرى، حيث كان يتم اختيار علاج كل حالة بحسب مكان السرطان ودرجته ومرحلته وحالة المريض.

وكان هدف العلاج هو إزالة السرطان من جسد المريض من غير تدمير الأعضاء السليمة حيث يعد مرض السرطان عبارة

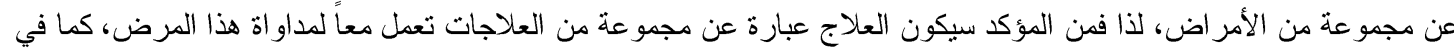
الثكل (3) الذي يوضح العلاقات المنبادلة بين الاقسام الرئيسة للمسنشفى الاشعاعي والطب النووي وهي منغيرة بحسب المشروع. 


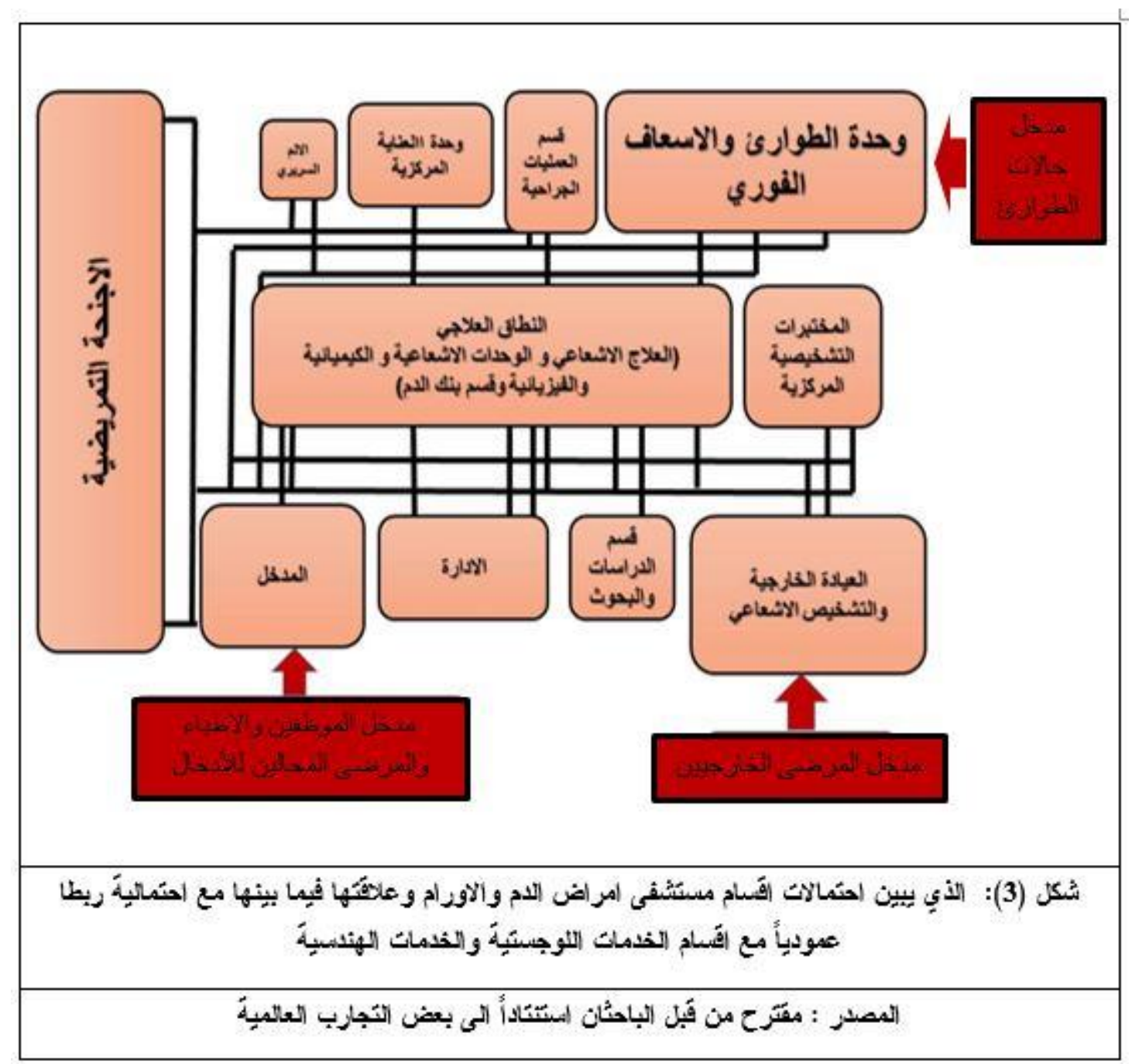

اما الاقسام التي تتميز فيها المستثفى عن باقي المستثفيات هي اقسام النطاق العلاجي واقسام الطب النووي اولا: اقسام النطاق العلاجي: ويشمل: (قسم العلاج الفيزيائي، وقسم العلاج الاشعاعي، وقسم العلاج الكيميائي)

physical therapy (1) قسم العلاج الفيزيائي (العلاج الطبيعي)

وهو القسم الذي ينت فيه معالجة المرضى بواسطة فعالية التدليك اليدوي و الميكانيكي، والعلاج الحراري، والعلاج المائي، فضلا

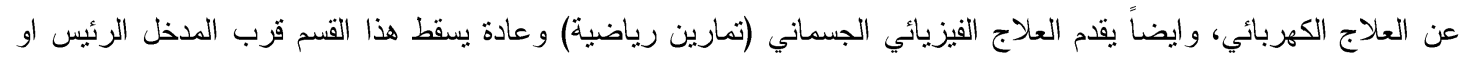

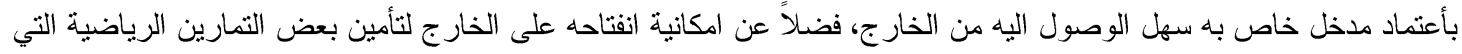

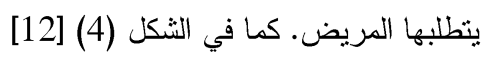




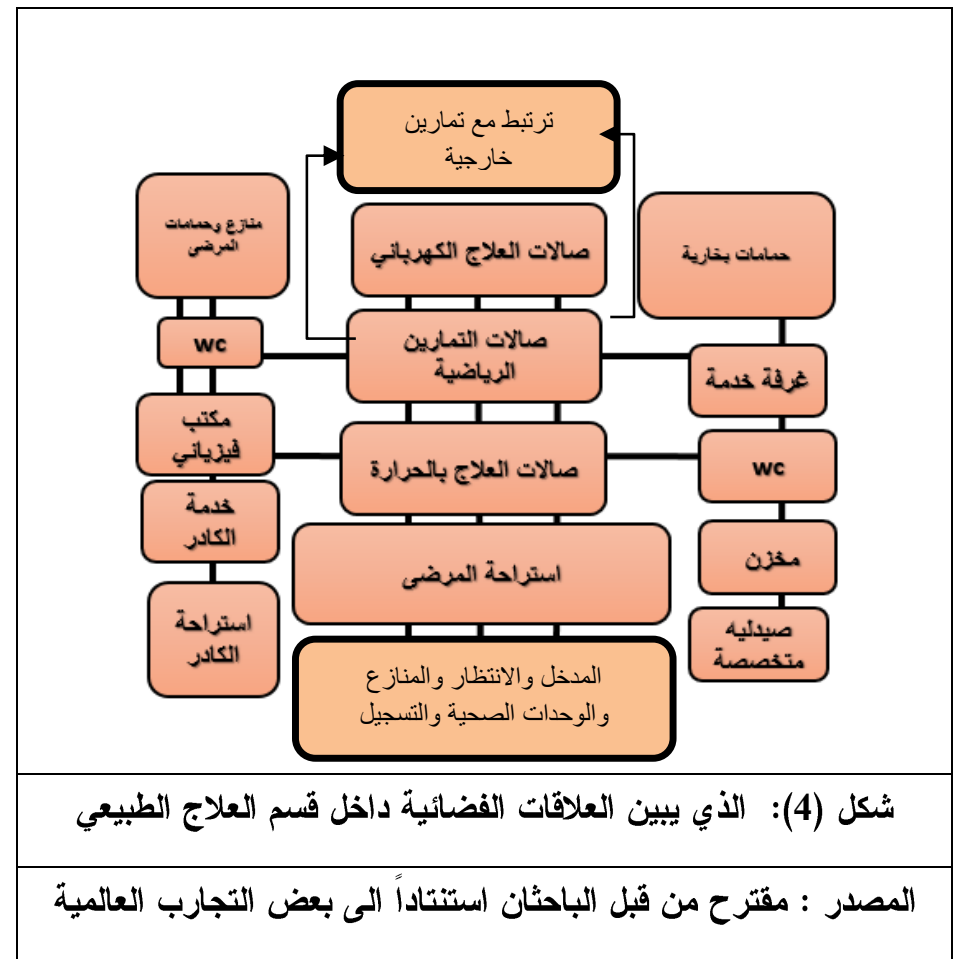

(2) قسم العلاج الاشعاعي:Radiation therapy

وصف عام لقسم العلاج الاثشعاعي: وهو القسم الذي يعطى فيه العلاج الإثعاعي الذي أصبح محددا للغاية ويركز حصراً على المنطقة

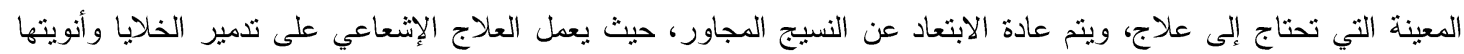

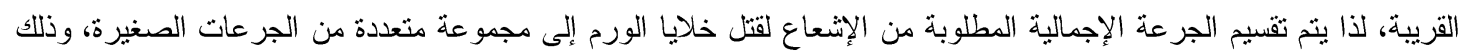

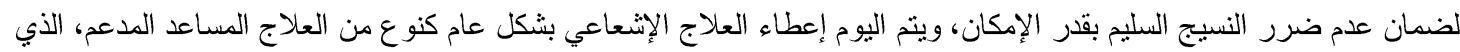

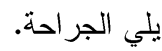

تصميم وتخطيط قسم العلاج الاثتعاعي: يتعاون كل من الطبيب الثنعاعي و الفيزيائي الفني بتحديد كمية الاثشعاع و الزاوية ومدة التخطيط

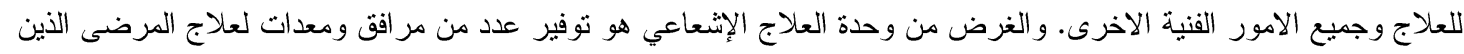

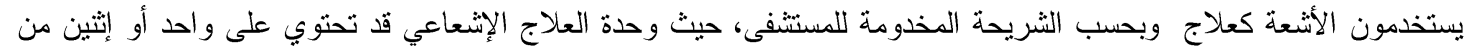

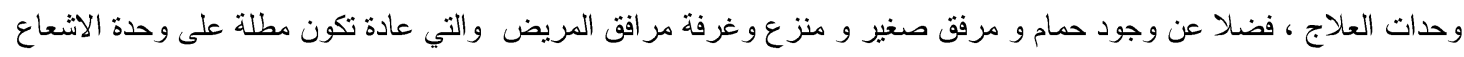

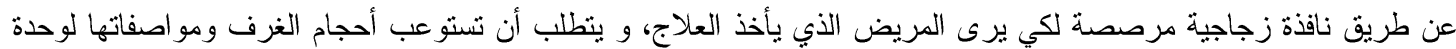
العلاج الإثعاعي توصيات الثركة المصنعة للمعدات، و يحتوي القسم ايضا غرف سيطرة على المعجلات الفيات الخطية يسيطر فيها الملاكل

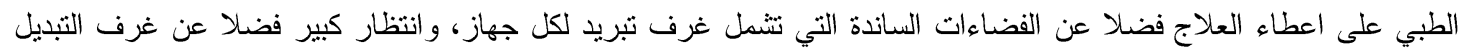

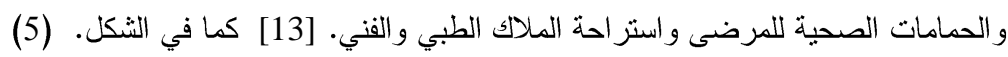




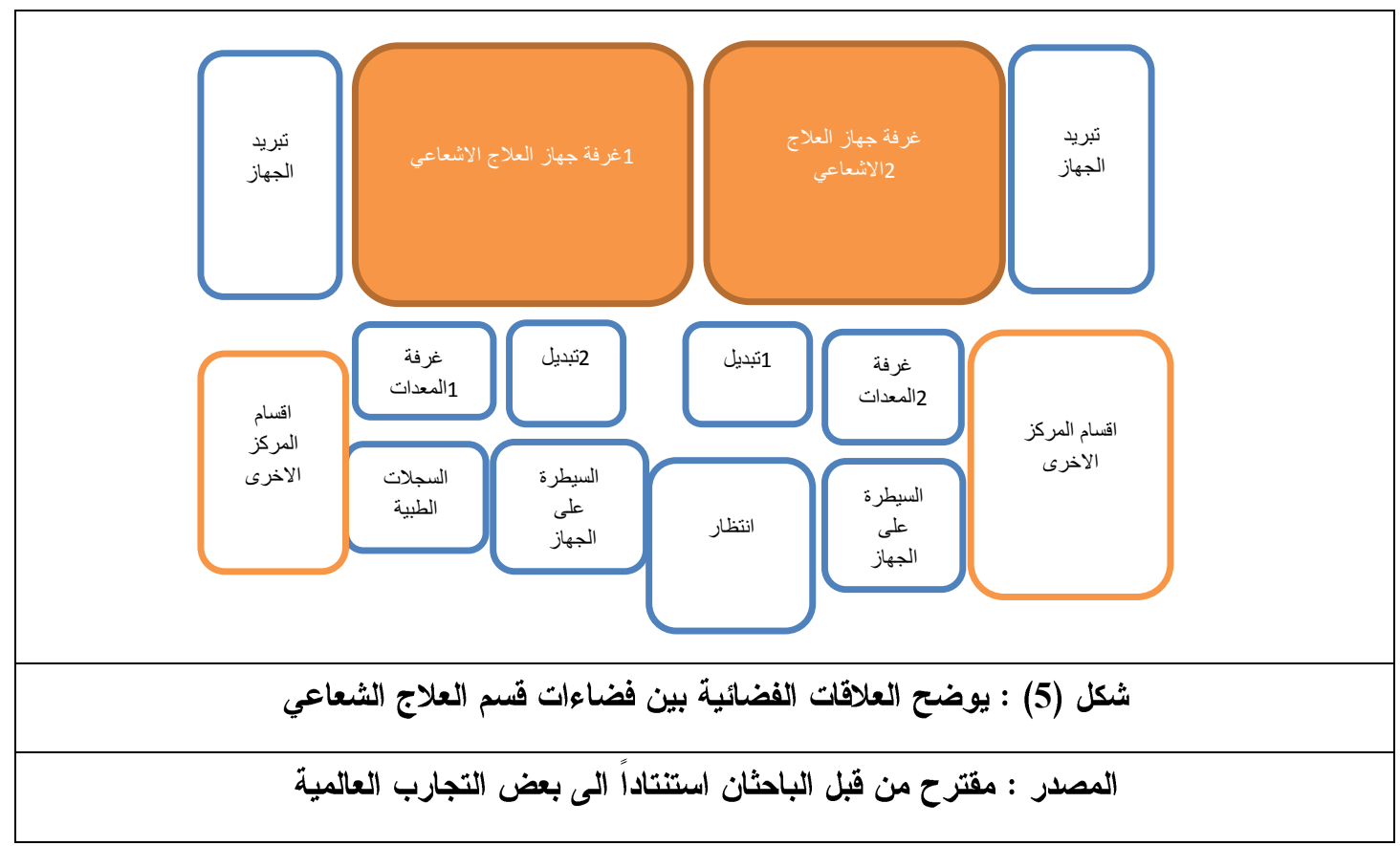

وفي بعض الاحيان هناك فضاء يخصص لأستر احة المرضى بعد العلاج الاشعاعي الذي يحتوي على اسرة ومكان لجلوس

المر افقين للمرضى ويفضل ان بطل على مناظر طبيعية.

المعالجات البيئية في قسم العلاج الاثثعاعي: غرف المعجل الخطي تمتاز ببناء من الكونكريت بسمك لا يقل عن (50م) ويصل الى (100 سم)، مع تدعيم الجدران و السقوف بالرصاص وذللك لضمان حماية البيئة الخارجية، فضلا عن التقوب التي توجد في مفاتيح

الكهرباء ترصص لمنع التسرب الاشعاعي. كما في الثنكل (6).

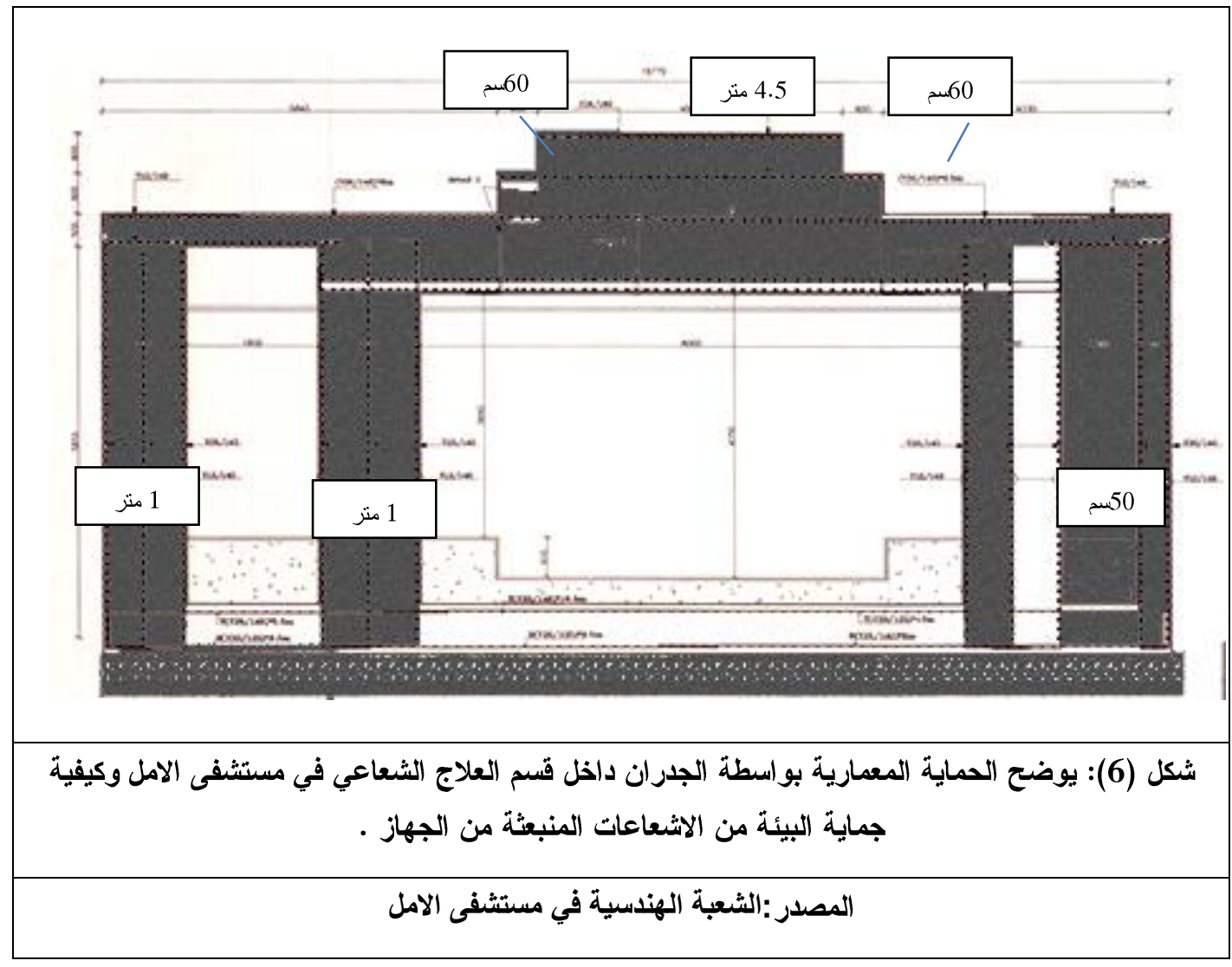


ويفضل ان يقع قسم العلاج الاشعاعي في السرداب او في الطابق الارضي ولا يبنى فوقها شيء لضمان الحماية التامة من الاثعاع، فضلا عن استعمال النو افذ من الزجاج المرصص واستعمال الباب المصنوع من مادة الفرثاس والرصاص بسك ولك ( 15سم) الذي يمتاز بالاحكام التام لكي يمنع تسرب الاشعاع الى الخارج كما في الثكل (7)، مع وجود مدخل جانبي و غير مباثشر الى الجهاز وذلك لتوفير الحماية الاضافية من الاشعاع كما في الثكل (8) [14].

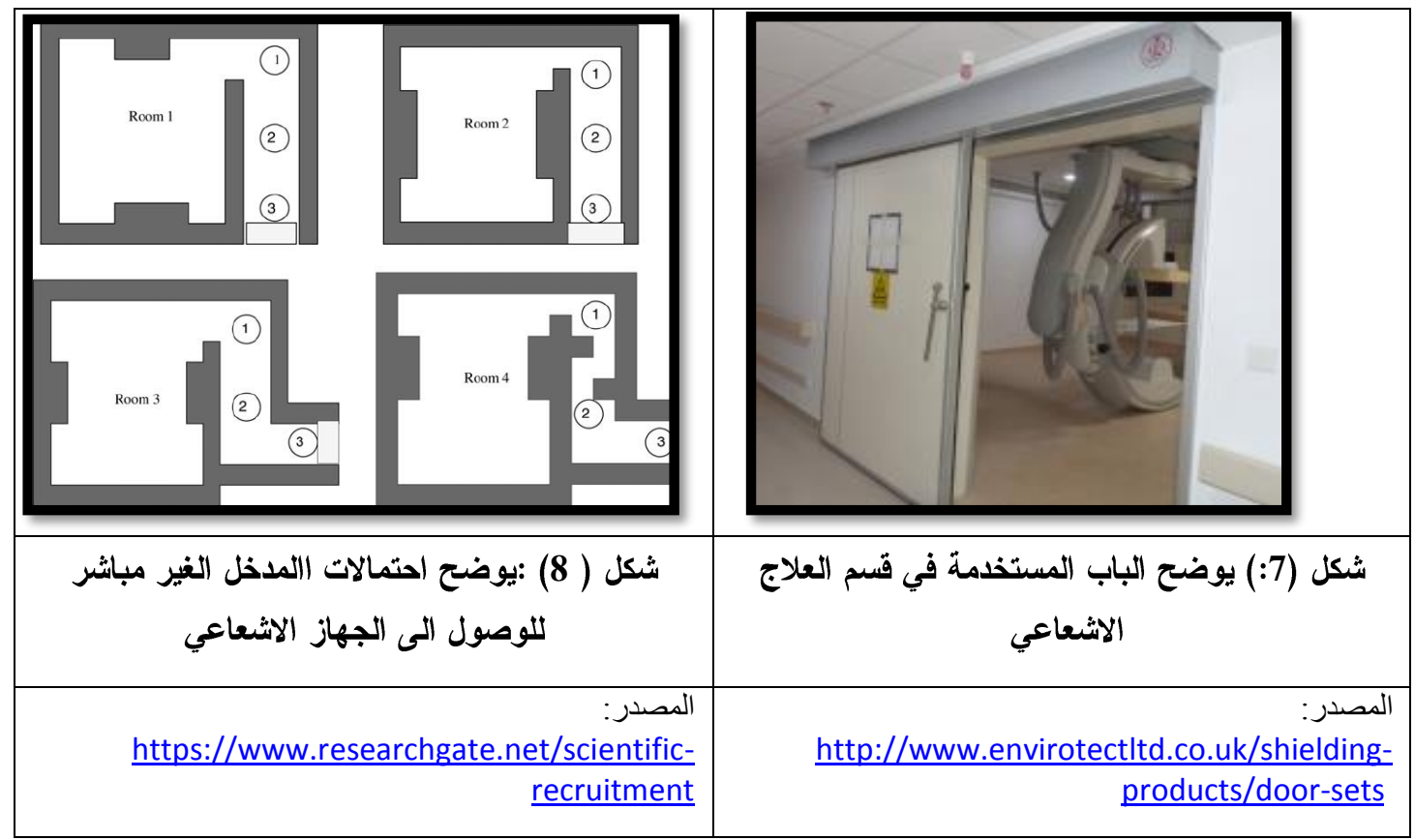

الجواتب النفسية والاجتماعية في قسم العلاج الاثعاعي: ان التصميم الجيد لقسم العلاج الاشعاعي يعزز من اهمية الخدمات المُقدمة

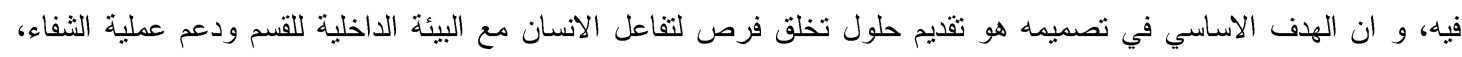
ولكون المريض المستلقي للقيام بالفحص لا يرى امامه سوى السقف فيجب توفير فرص كبيرة لتغيير مخطط السقف من خلال دمج

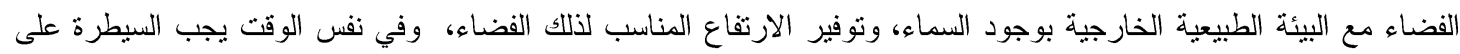

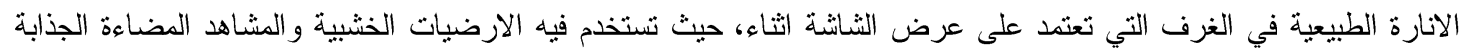

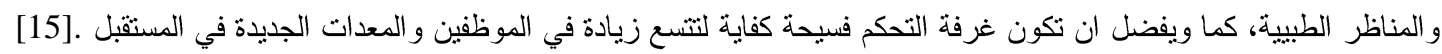
وفي الاشكال (9)و (10) يوضحان امثلة عن القسم الاشعاعي.

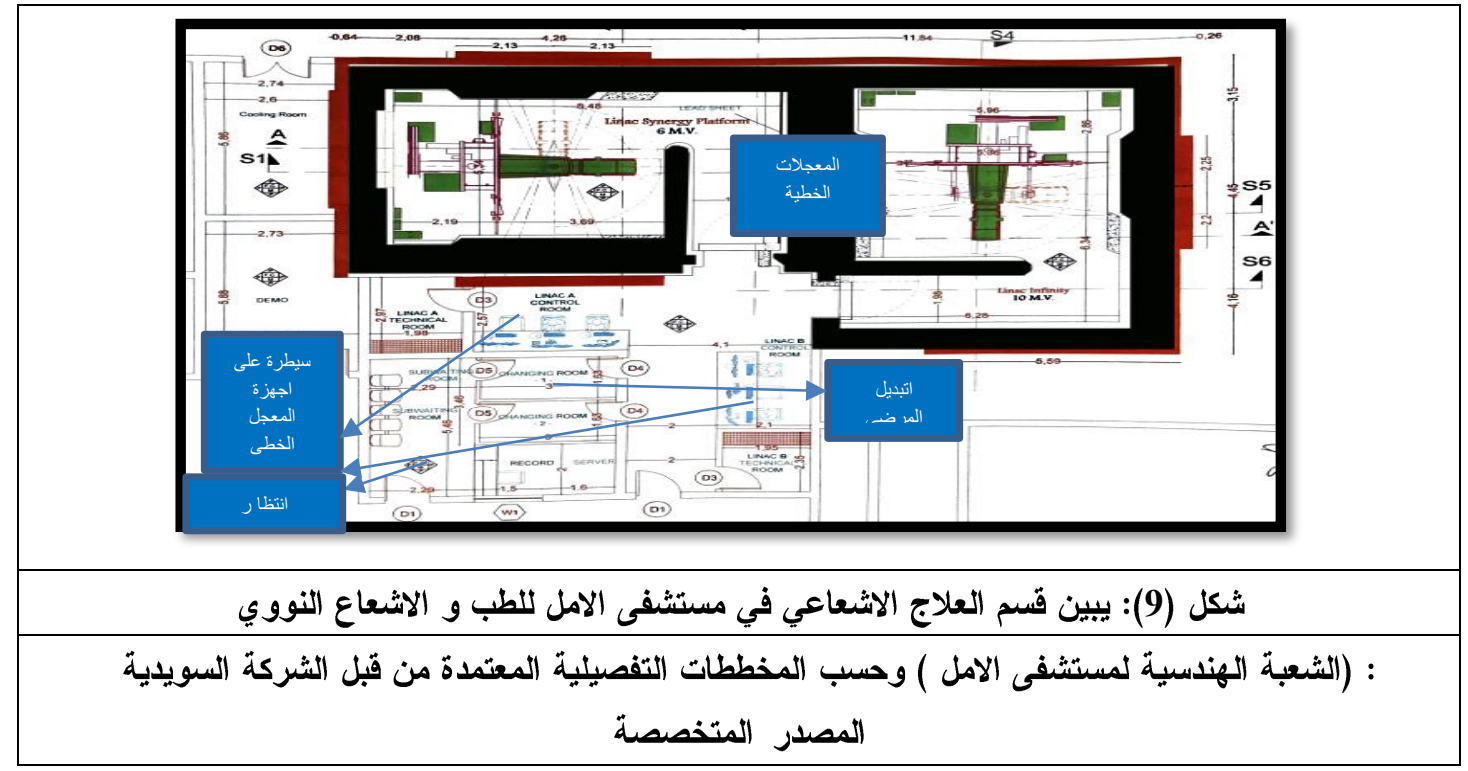




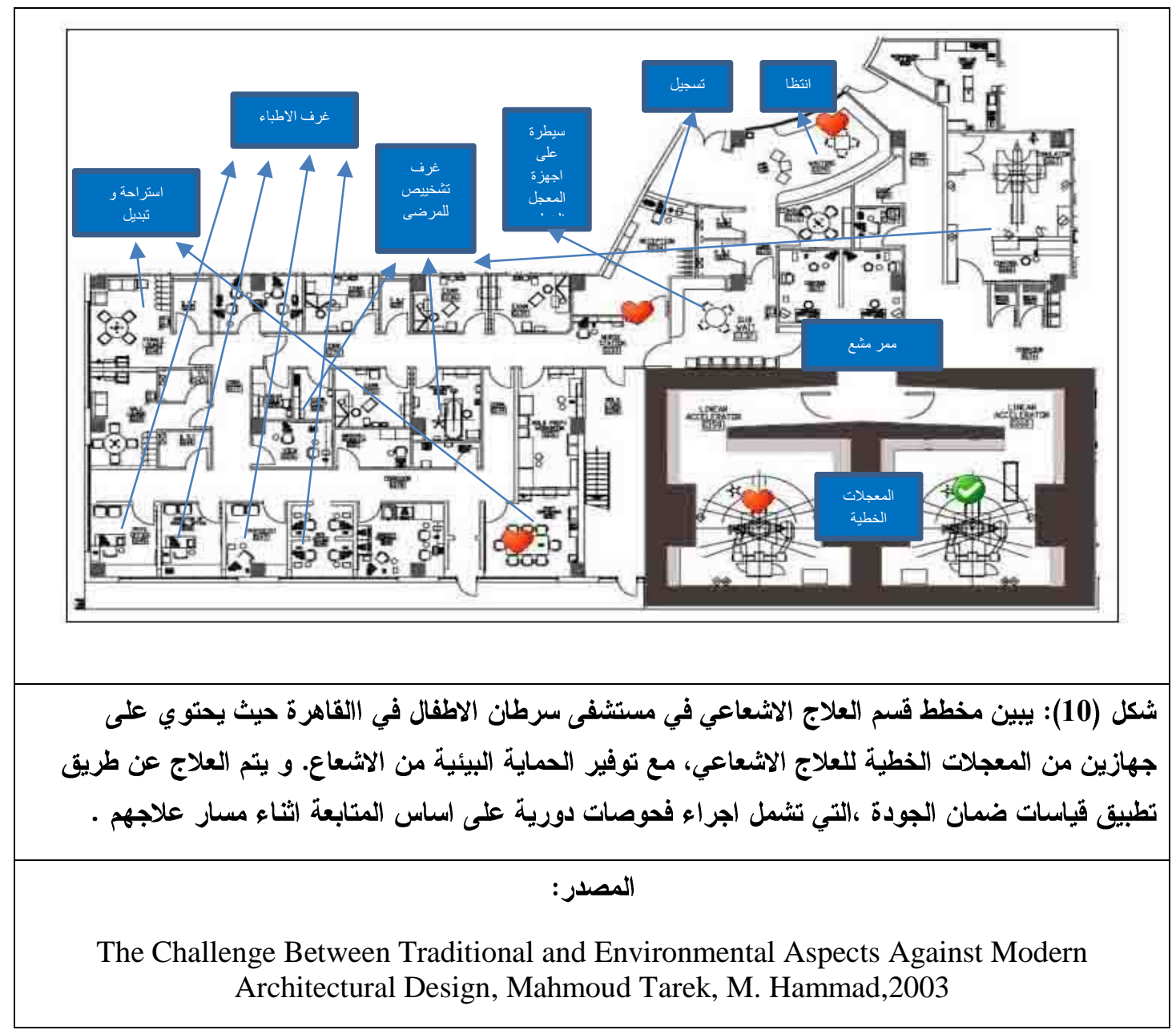

: Chemical therapy قسم العلاج الكيميائي

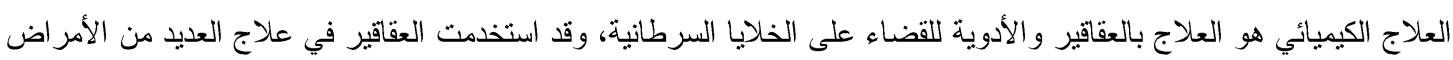

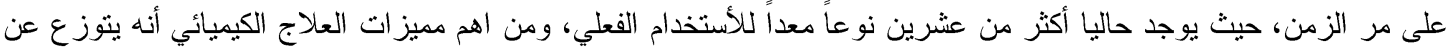

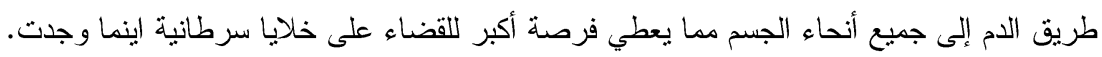

تصميم و تخطيط قسم العلاج الكيمياوي: يشمل قسم العلاج الكيميائي الفضاءات الاتية: (المدخل الذي يشمل مناطق الانظار

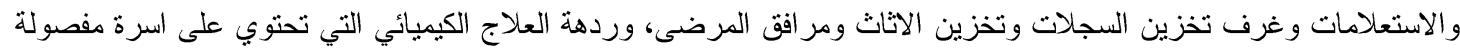

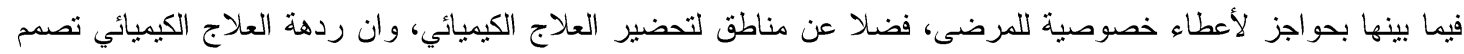

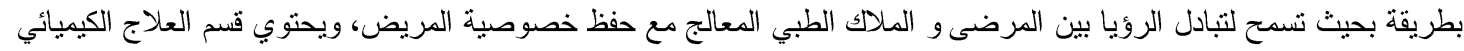

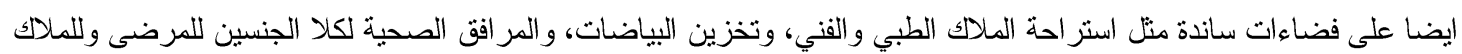

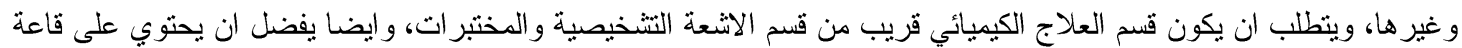

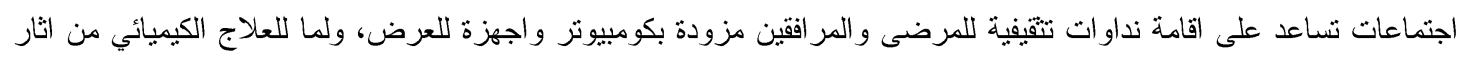

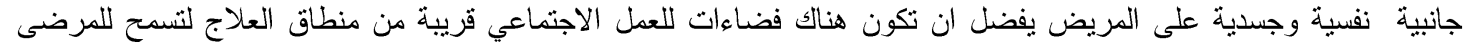

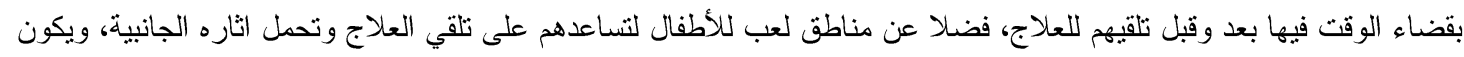

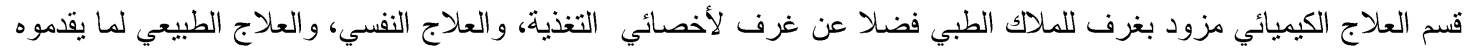

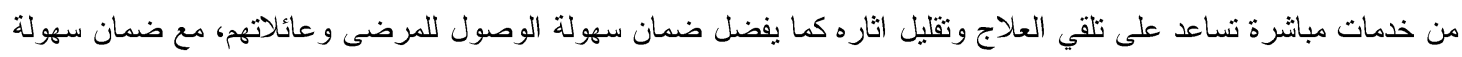

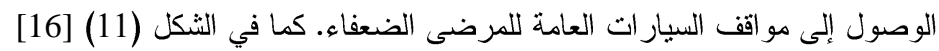




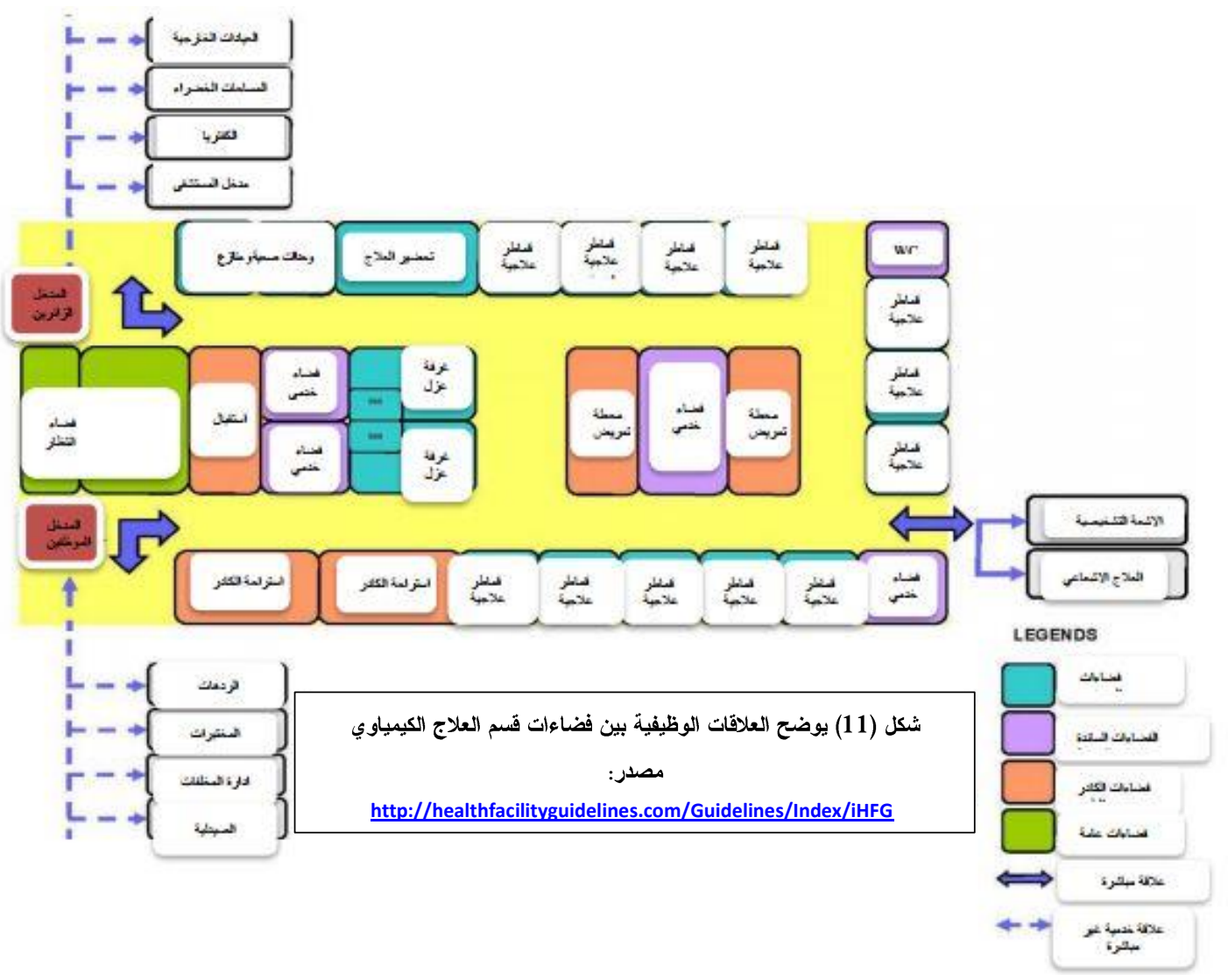

المعالجات البيئية

المعالجات البيئية في قسم العلاج الكيمياوي: نقتصر اثار العلاج الكيمياوي على البيئة على المخلفات الناتجة منه، حيث يفضل معالجة

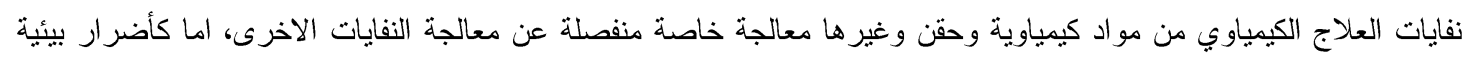

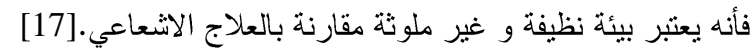
الجو انب النفسية و الاجتماعية في تصم مقسم العلاج الكيمياوي: يفضل أن تكون الانهاءات الداخلية بما في ذلك الأرضيات و الجدران

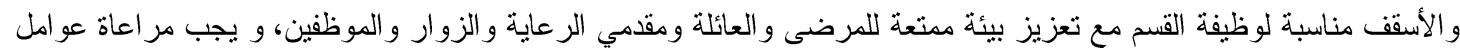

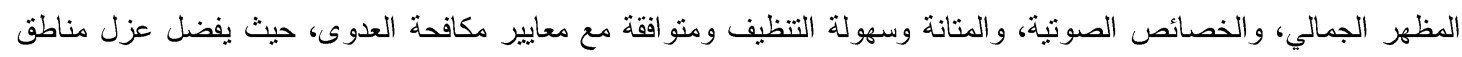
العلاج عن ضوضاء الدذل و الانتظار وحركة الكادر وتحقيق الخصوصية للمرضى قدر الامكان [18] كما مبين في الثنكل (12)

(13) 9

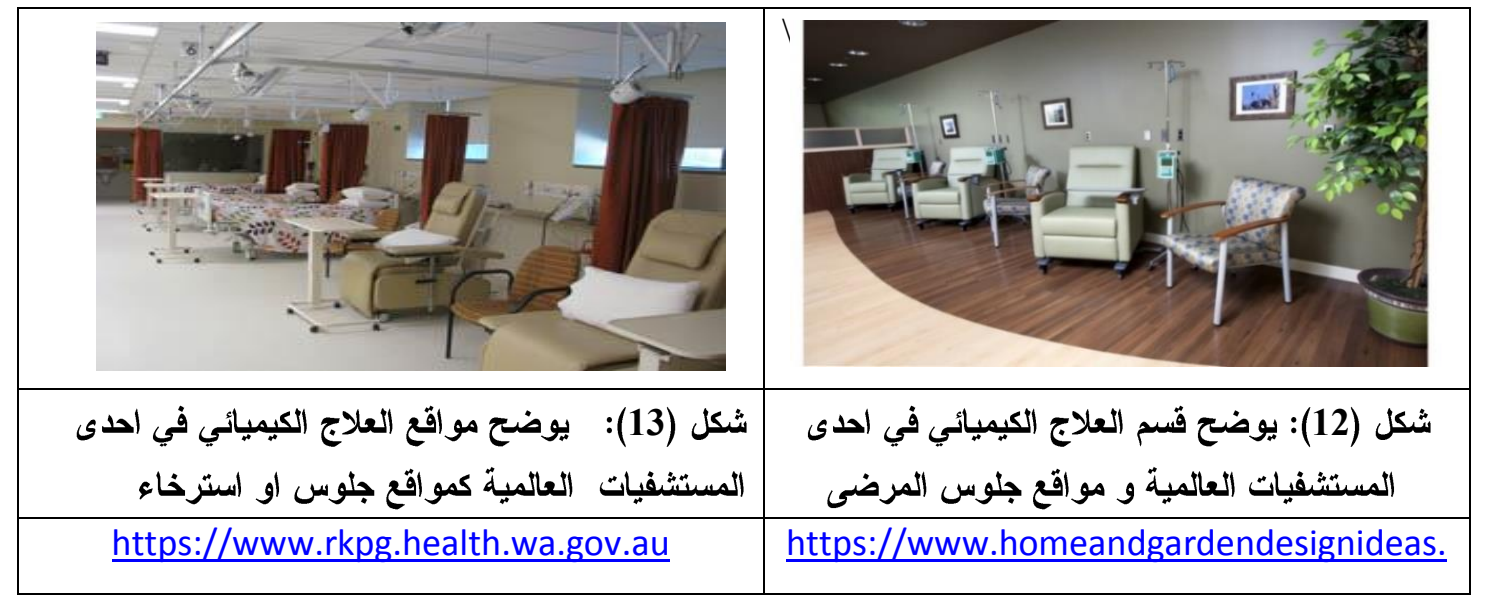


ثانيا-قسم الطب النووي: ان الطب النووي هو مجال متخصص في التصوير يستخدم كميات من المواد المشعة اللازمة كمواد للفحص، الميزة الرئيسة للطب النووي هي القدرة على تحديد وظائف التمثيل الغذائي، وذلك عن طريق النظائر المشعة إما عن طريق الفم، او عن طريق الاستتشاق، أو عن طريق الوريد، أو في اختبار حالات عن طريق الحقن المباشر للحصول على تقييمات تتخيصية

تصميم قسم الطب النووي: ينقسم الطب النووي الى تشخيص وعلاج، حيث ويتكون قسم الطب النووي من فضاءات تشخيصية منمنلة بجهازي وة comma camera وpt. scan ،ضضلا عن المختبر الحار لتحضير المادة المشعة، و واستر احة مرضى، و انتظار مر افقين، و استر احة الملاك الطبي و الفني المتخصص، و فضاءات خزن و فضاءات خدمة وغير ها كما في الثنكل (14)

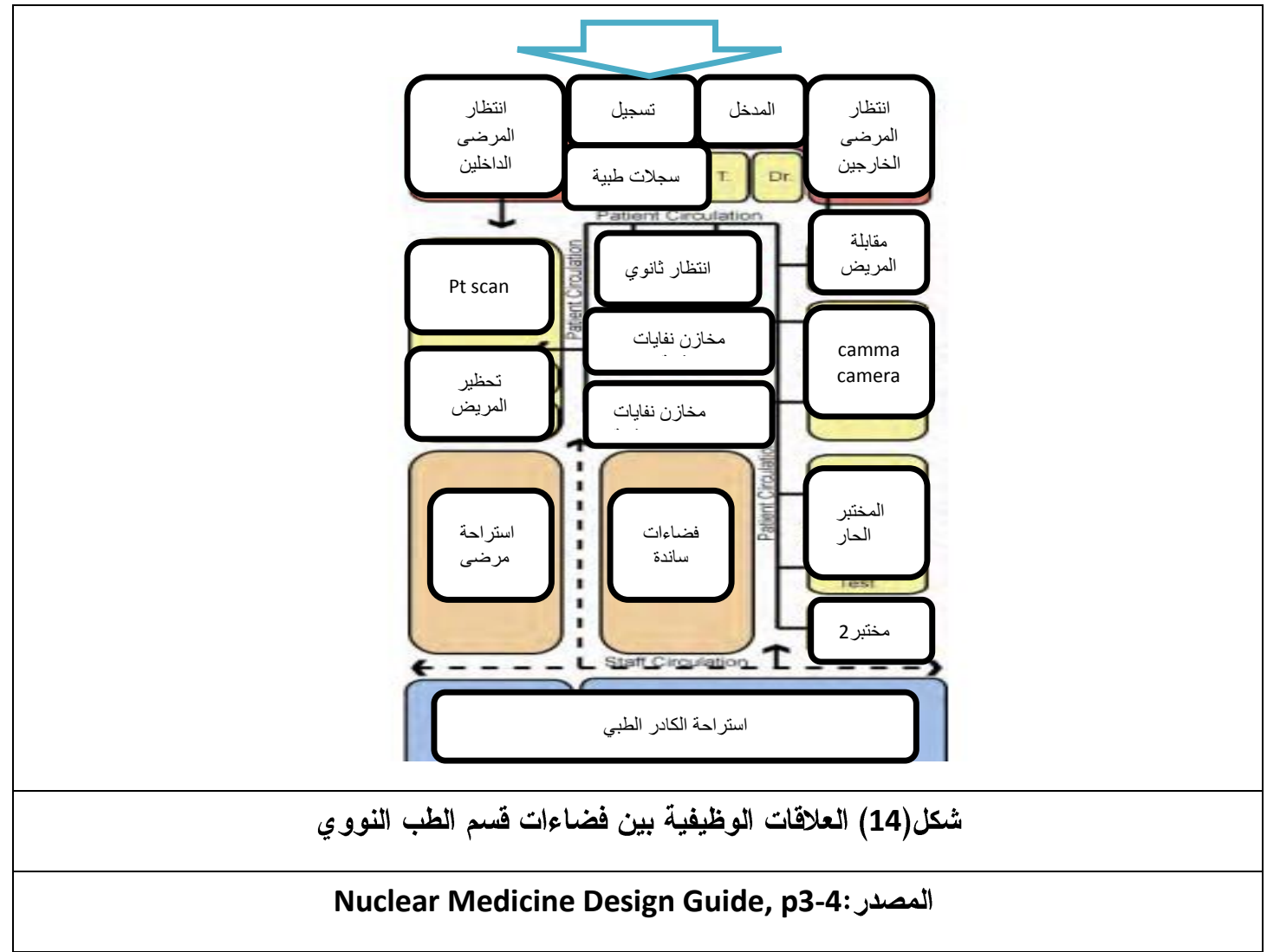

المعالجات البيئية في قسم الطب النووي : تتمثل المعالجات البيئية بعدة امور منها عزل حمامات المرضى المزروقين المادة المشعة عن الحمامات الاخرى وكذلك فصل انابيب التصريف الخاصة بها عن الانابيب الرئيسة للتصريف وذلك بسبب احتو ائها على مواد

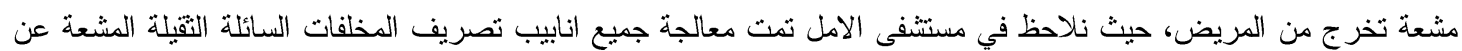
الانايبي التصريف الاخرى، و تغلف كافة انايب التصريف الخاصة بها بو اسطة غطاء من الرصاص بسمك (40-25 سم)، و يذهب الانبوب الى الحوض الرئيسي الذي يقع خلف مبنى الطب النووي ومرتبط به ثلاث احو اض ثنانوية كل حوض نتجمع فيه المباه المشعة الاتية من الحوض الرئيسي لمدة (81)يوم لكل حوض بعدها تنطلق الى فناة التصريف الرئيسة كونها تخلصت من نسبة الاشعاع التي نئي تحتويها [20]، كما في الثكل(15). 


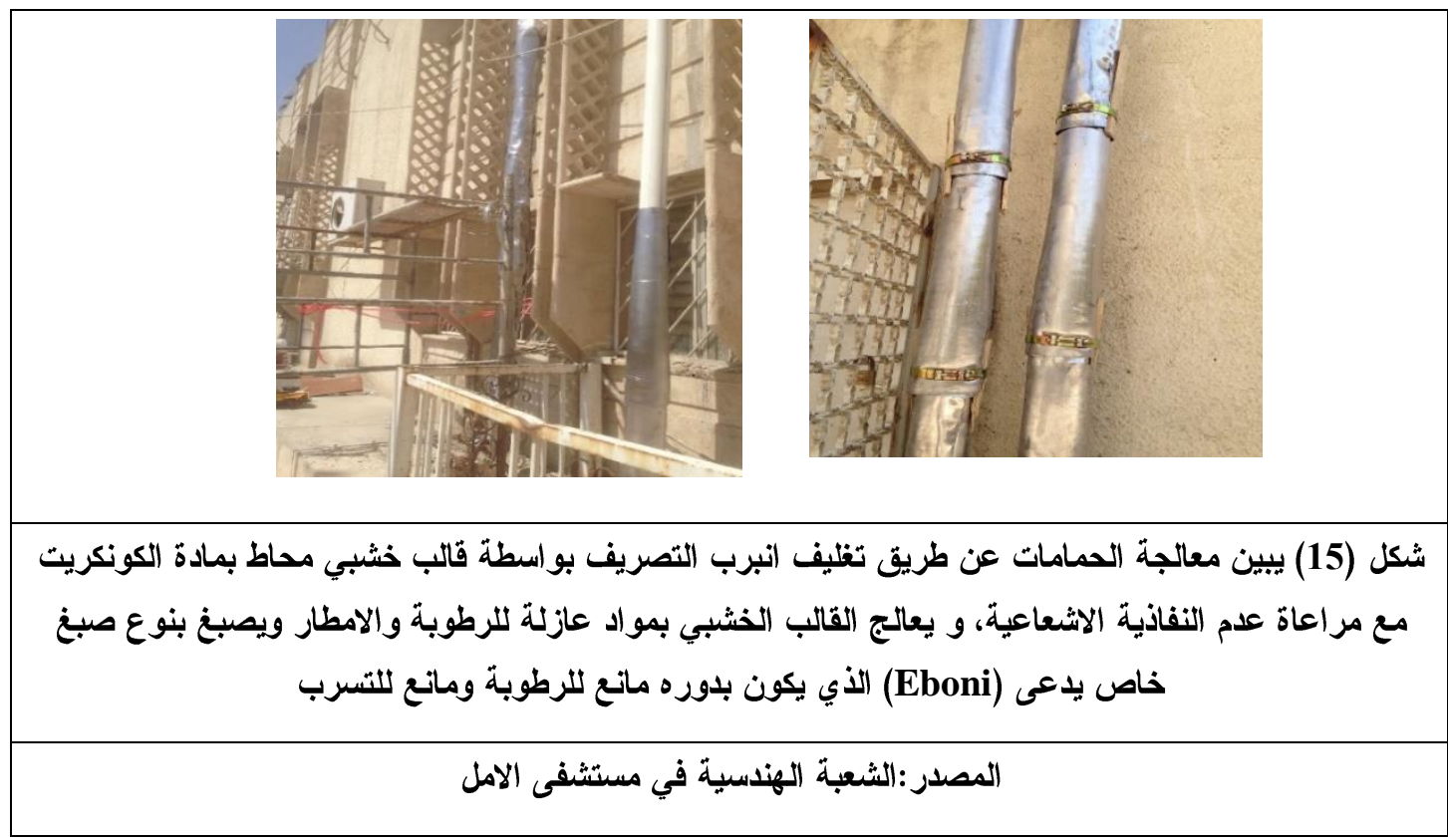

فضلا عن النفايات المشعة حيث يتم التخلص منها بشكل منفصل عن النفايات الاخرى وهي عادة تتمثل بالعبوات التي تحتوي

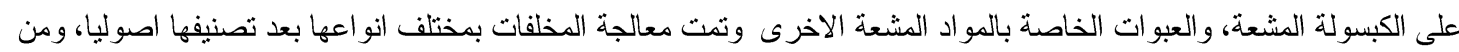
ثم وضع النفايات في اماكن معزولة ( مخازن سطحية اوتطمر تحت الارض) حيث يضمن ابعاد الخطر عن الناس والبيئة [17].

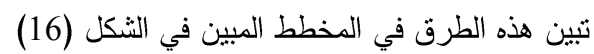

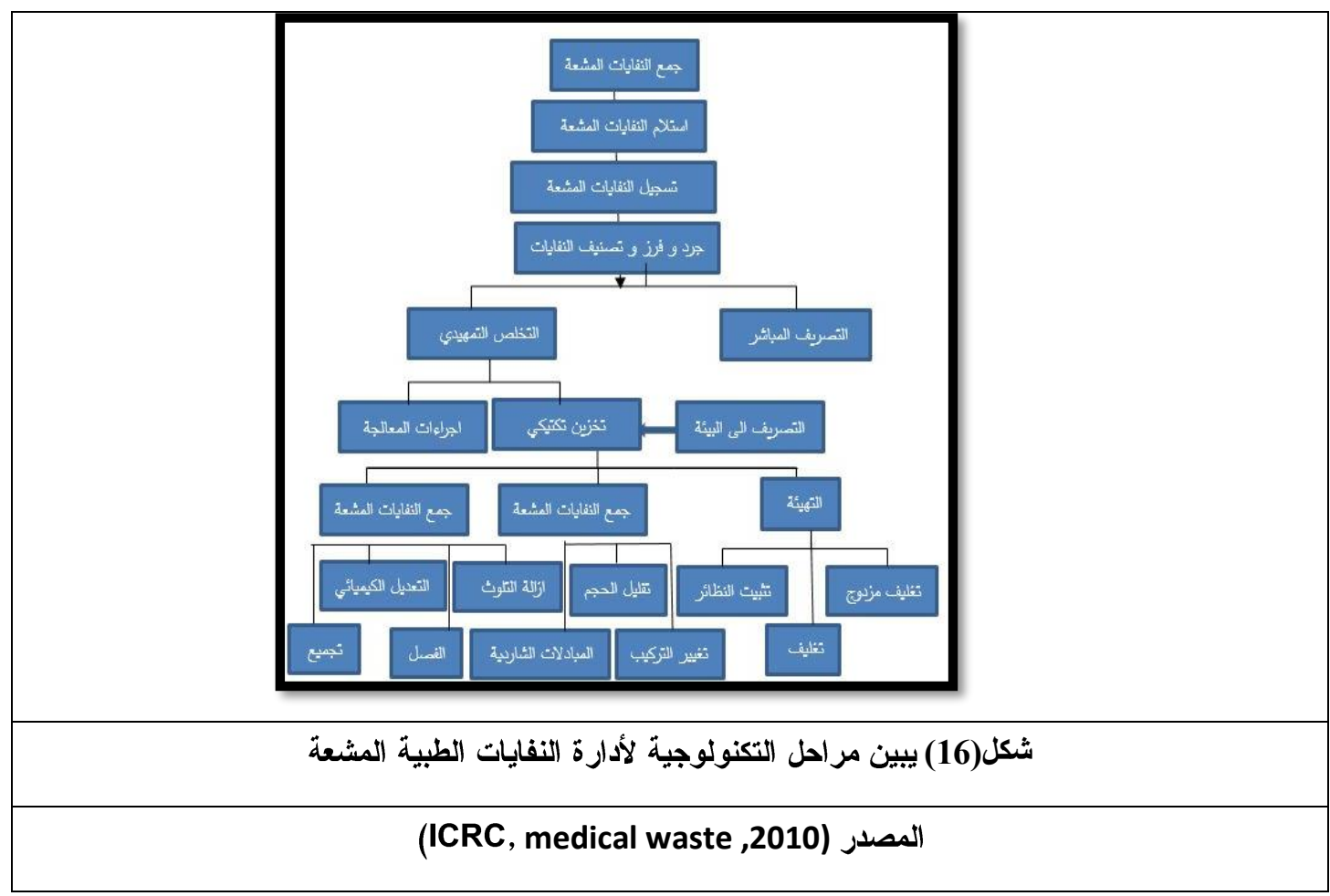

7-الار اسة النطبيقية - التقويمية لعينة بحثية محلية:

استتاداً الى استخلاص مؤشرات الإطار النظري عن مراجعة وتحليل مجموعة واسعة من التجارب العالمية والعربية والتي شملت المؤشرات التخطيطية والتصميمية لمسنتفيات امر اض الدم والاورام، ودر اسة تصميم الاقسام داخلها، فضلا عن علاقتها ونها ونها 
بالتصميم الحضري للمنطقة المحيطة، حيث خلصت هذه الدراسةالموسعة التي يمكن عرضها بشكلها التكاملي في هذا البحث الى

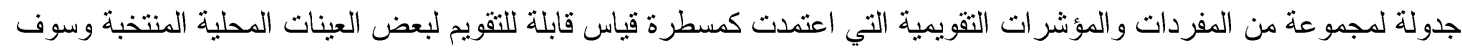
تستعرض هذه الدر اسة التجربة المحلية في مستشفى الامل للطل و الاشعاع النووي في بغداد وبحسب الاتي :

(1)- توصيف العينة البحثية - مستشفى الامل للطب والاشعاع النووي:

\begin{tabular}{|c|c|}
\hline \multicolumn{2}{|l|}{ البطاقة التعريفية } \\
\hline مستتفى الامل الوطني للاثتعاع والطب النووي & اسم المستثفى \\
\hline بغداد - ساحة الاندلس & موقع المستشفى \\
\hline (200) سريز & سعة المستشفى \\
\hline تم اعادة تأهيل قسم العلاج الاشعاعي من قبل شركة اليكتا السويدية المتخصصة & للمستثشفى المنفذة \\
\hline 1969 وتم اعادة تأهيلها في العام(2015) & سنة الفتتاح \\
\hline طابق ارضي+ 3 طو ابق & علد الطو ابث \\
\hline يحتوي المستشفى على أربع ردهات الثين للرجال وو للنساء، وردهن & التواع الاجنحة \\
\hline أثثي عشرعيادة استثارية بالاورام في مبنى الادارة وخمسة عيادات استشارية في مبنى الطب النووي & علد العيادات \\
\hline 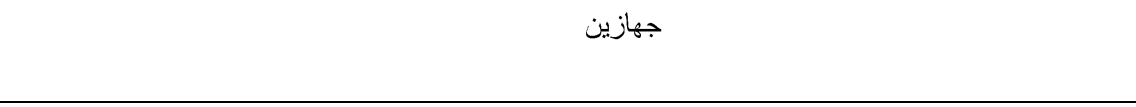 & العلاج الاشعاعي اجزة \\
\hline 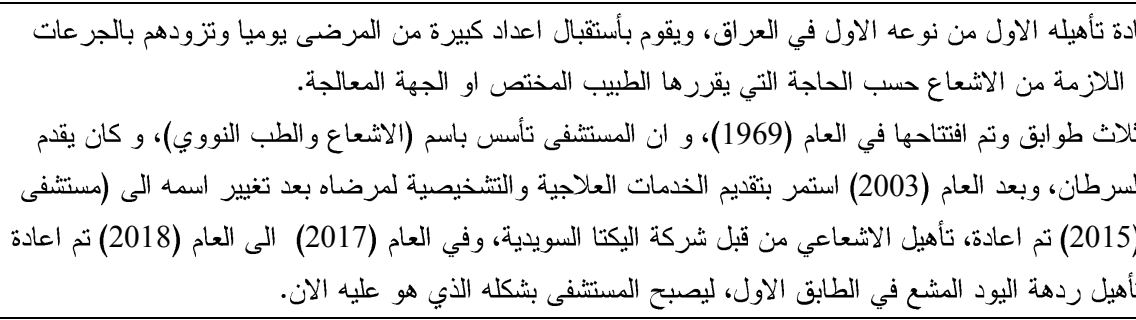 & 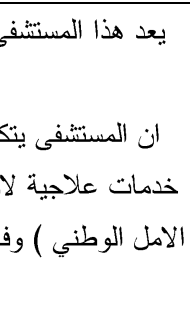 \\
\hline
\end{tabular}

ملاحظة: لأغر اض التوسع في المعلومات الخاصة بهذه العينة نوصي بمر اجعة المصدر: "الاسس التخطيطية و التصميمية لمر اكز امر اض الدم والاور ام في العراق" / در اسة ماجسنير / جامعة بغداد - كليه الهندسة - 2019 و المعدة من قبل الباحثة. 


\section{جدول (3)}

يبين تقويم العينة البحثية حسب المؤشرات المستخلصة من الإطار النظري لمستثفى الامل الوطني للأثعاع والطب النووي

\begin{tabular}{|c|c|c|c|c|c|c|c|c|}
\hline \multicolumn{5}{|c|}{ التقبيم } & \multirow[b]{2}{*}{ 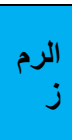 } & \multirow[b]{2}{*}{ مقومات المؤشر } & \multirow[b]{2}{*}{ مؤشرات القيم } & \multirow[b]{2}{*}{ 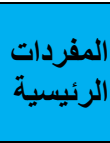 } \\
\hline | & ف ضبعي & متوسط & جيد & جيا & & & & \\
\hline & & 3 & & & 1.1 & الموقع ضمن حدود واضحة تضمن & استقالية الموقع عن & \\
\hline & & 3 & & & 1.2 & ضمان وجود شوارعة رئيسة و مو اقف & سهولة الوصول الى & \\
\hline & & 3 & & & 1.3 & ذو مسافات متقاربة عن المناطق & الموكزيته نسبة الى المخدو & : \\
\hline & 2 & & & & 1.4 & ضمان البيئة الطبيعية لعموم الموقع ومحيطة & البيئة الطبيعية & t \\
\hline & & 3 & & & 1.5 & وجود مو اقع كافية لأمكانية التوسع & المكانية التوسع & $\xi$ \\
\hline & & 3 & & & 1.6 & ضمان حماية كافة المو اقع المحيطة & حماية المو اقع & $\underline{\underline{E}}$ \\
\hline & & 3 & & & 1.7 & للمرضى و المر افقين و الكادر الطبي & كفاية مداخل المشروع & \\
\hline 1 & & & & & 1.8 & للمرضى و المر افقين ولطو ارئ & كفاية مو اقف السيار ات & \\
\hline & & 3 & & & 2.1 & و ان المركنولو مو اكبة للتطور الطبية في تصميم العلمية & استقلالية الاقسام & 5 \\
\hline & & & 4 & & 2.2 & ضمان استقلالية وحماية الاقسام و عدم & 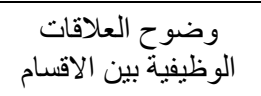 & 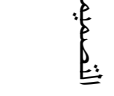 \\
\hline & & 3 & & & 2.3 & ضمان توسيع كافة الاقسام و عدم & توسيعات الاقسام & $\frac{2}{5}$ \\
\hline & & 3 & & & 2.4 & وضوحية وكفاية وظائف كل قسم & وضوحية وكفاية & 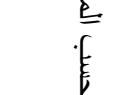 \\
\hline & & 3 & & & 2.5 & الحركة الاساسية وحركة كل قسم & وضوحية الحركة & $\underline{E}$ \\
\hline & 2 & & & & 2.6 & للمر اجعين و المرضى و المر افقين & تامين مو اقع التجمع & E. \\
\hline & & & & 5 & 2.7 & استقلالية سكن الاطباء والكادر الفتي & سكن الاطباء و الكادر & \\
\hline & & & 4 & & 3.1 & ضمان حماية كافة المباني من & حماية مباني المركز & : \\
\hline 1 & & & & & 3.2 & 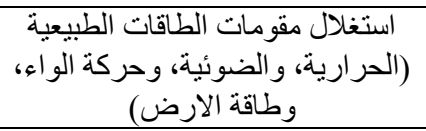 & 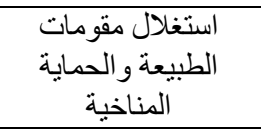 & $\sum_{0}^{2:}$ \\
\hline 1 & & & & & 3.3 & 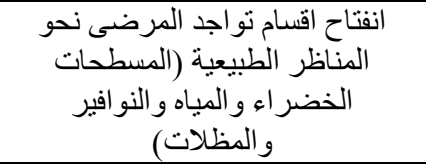 & 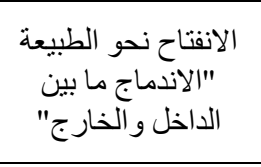 & 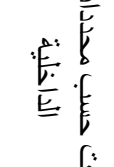 \\
\hline & 2 & & & & 3.4 & استقلالية المشروع عن المو اقع & الحماية من المو اقع & $\underline{\xi}$ \\
\hline & & & 4 & & 3.5 & 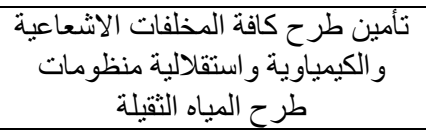 & طرح الفضلات & Ev: \\
\hline
\end{tabular}


Journal of University of Babylon for Engineering Sciences, Vol. (27), No. (2): 2019.

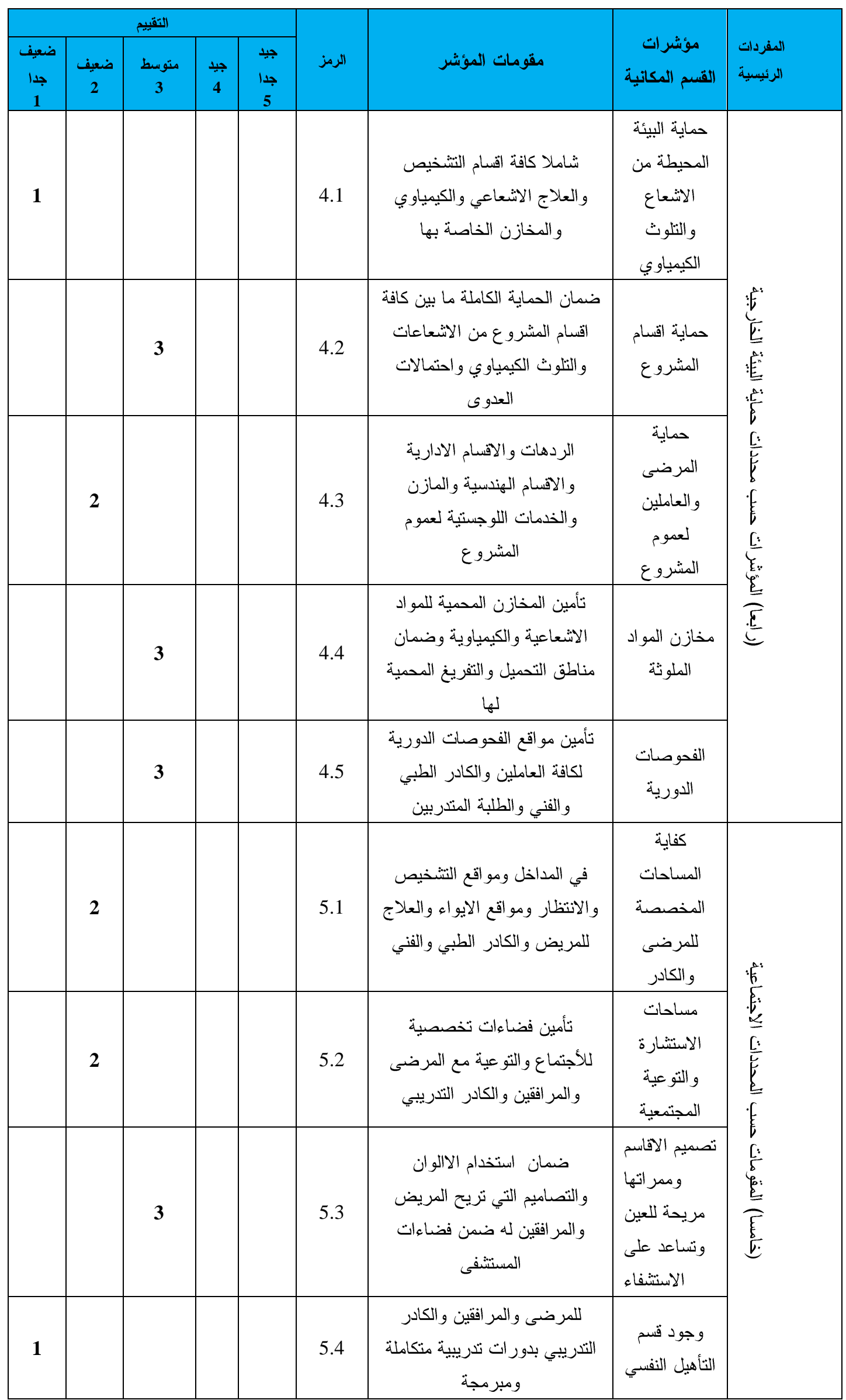




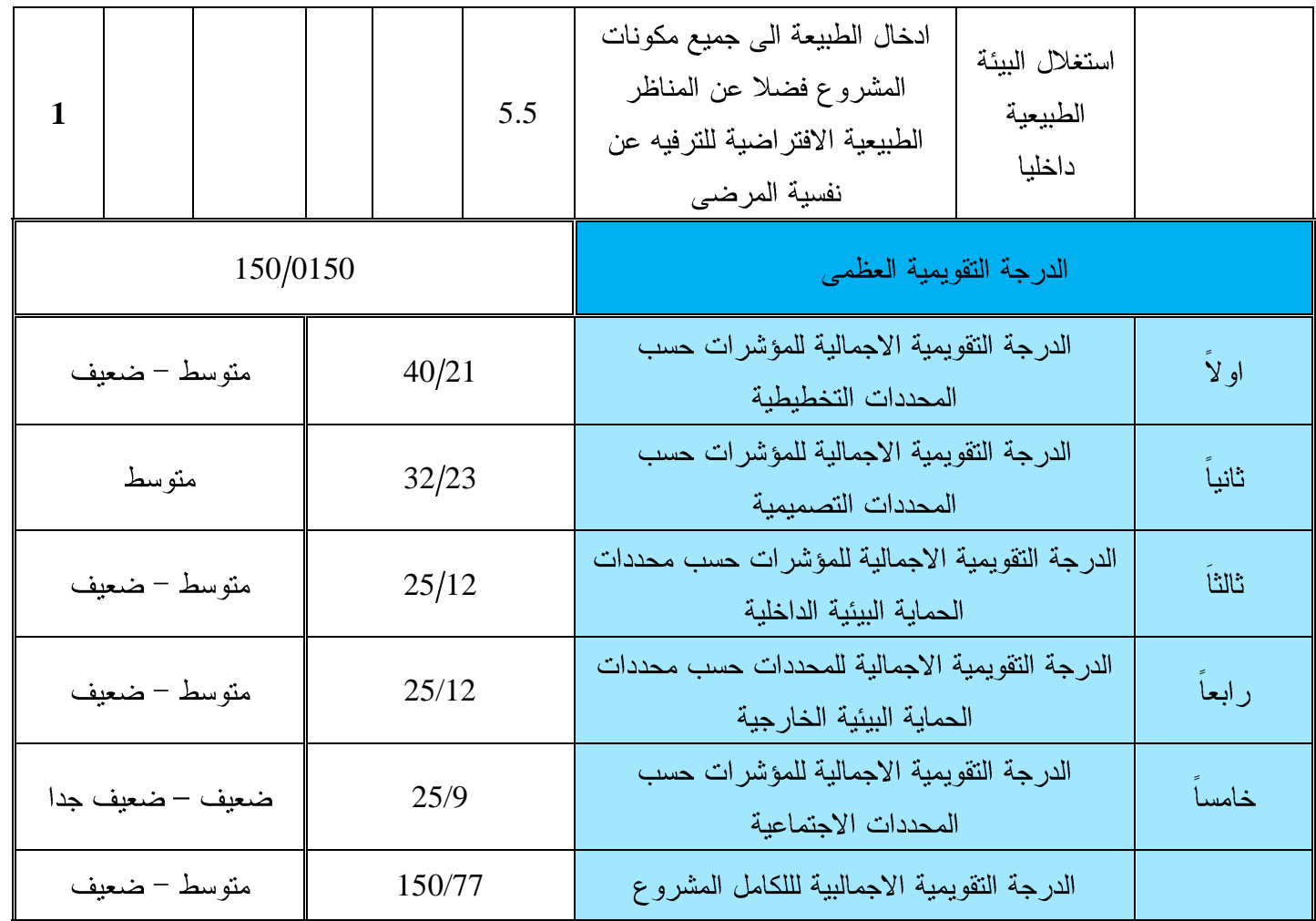

ملاحظة: أجري الثقويم حسب رؤية الباحث ومخرجات الاسنبانة التطبيقية والمفابلات الثخصية المباثرة التي قام بها الباحث مع الملاك الطبي و الفني و الهندسي فضلا عن عن المرضى وضه ومر افقيهم.

\section{(2) الاستتتاجات الخاصة بالتجربة المحلية - مستثفى الامل للأثعاع و الطب النووي - في بغداد:}

1-ان موقع المستثفى وسط مدينة بغداد، و بالقرب من عدد من المسنتفيات الاخرى و مباني مهمة عديدة اكسب المبنى ايجابيات و سلبيات، حيث الايجابيات تكمن في قرب المستثفى من مباني المستثفيات الاخرى في حال لنزويد المستثفى بالخدمات الطبية

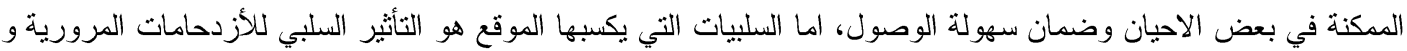

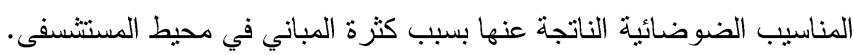

2- المستثفى يمثاز بمركزية و سط المناطق المخدومة، و وسط المستثفيات الاخرى لخدمة اكبر مساحة جغر افية ممكنة، حيث

$$
\text { تستقبل اعداد كبيرة من المرضى يوميا. }
$$

3-كذلك نشير اللى صغر موقف السيار ات المخصص بشكل عام للملاك الطبي و العاملين داخل المستشفى فقط، اما المرضى والمر اجعين

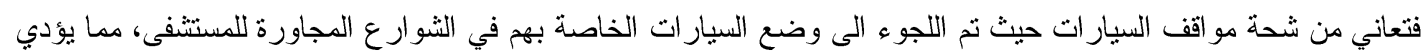
اللى تعقيد مناورة الحركة وظور التأثير السلبي على سهولة وصول المرضى الى المسنتفى و لا سيما بسبب اغلاق بعض الثنوارع احيانا مما يؤثر بالتالي على التصميم الحضري لكموقع المستثفى عموماً.

4-ان تصميم المستشفى و اضح نو عا ما وظيفياً ومن حيث استقلالية وكفاية الاقسام ووضوح الحركة الداخلية للملاك الطبي والمرضى، لكن كونه قديم جدا وان الصيانة لا تتم بشكل جذرب فيلجأ قسم الصيانه الى الحلول الترقيعية مما يؤثز سلبا على اداء اقسام

$$
\text { المستشفى واحتمالية خطورة التسريب الاشعاعي. }
$$

5-بسبب ازدياد الاصابات في الاونة الاخيرة بمرض السرطان في العراق، و بسبب كون المستثفى ذات تصميم قديم وغيرمخصصة

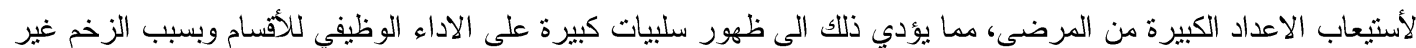
المتوقع و قلة الخدمات الطبية المقدمة من قبل المستشفى، فضلا عن عدم كفاية اماكن الانتظار للاعداد المنز ايدة كما ذكرنا سابقا 
مما يجعل بعض المرضى ينتظرون في الممرات الضيقة مما يسبب اعاقة في الحركة الداخلية داخل الاقسام وظهور الثد العصبي

$$
\text { و النفسي لعموم المرضى والمر افقين. }
$$

6بالتاكيد لا توجد حماية تكاملية متطورة لضمان مباني المستتفى من مؤثرات الصواعق والمرسلات لضمان حماية المبنى مثل

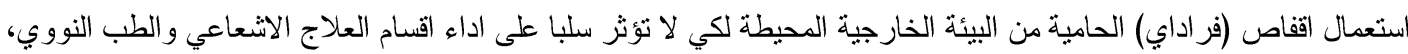
فضلا عن ضعف حماية البيئة الخارجية من الاشعاعات الملوثات الصادرة من القسم، مما يؤشر سلبية و اضحة في الاداء البيئي

7- لا يوجد قسم اعادة تأهيل خاص بالمستشفى، حيث يتم الاستعانه بقسم اعادة التأهيل النفسي الموجود في مسنتفى الاور ام في مدينة

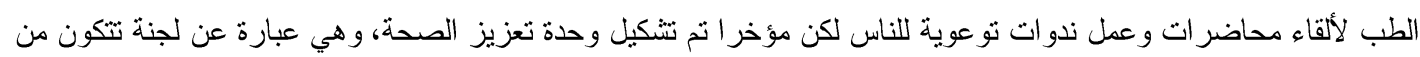
ثلاث اشخاص تعمل على دعم المرضى نفسيا ونوفير شاشات عرض الكترونية ووضعها في فضاءات الانتظار كبديل عن مشكلة افتقار المستشفى لقسم التأهيل النفسي.

8- ضمان الحماية الكاملة ما بين كافة اقسام المشروع من الاشعاعات و التلوث الكيمياوي، حيث تم اعادة تأهيل قسم العلاج الاشعاعي حيث أصبح محمي نو عا ما عن طريق جدار من الكونكريت بسمك (50سم) ومزود بطبقة من الرصاص، لكن الحماية لبست تامة

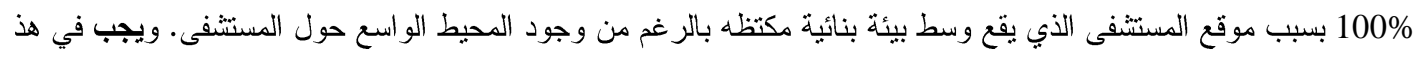
الحالة زيادة الحماية في المستثفى عن طريق منظومة مركزية من ماء (Ro) و التي تعمل على فلترة جميع المياه المستعملة في بي ولي

المسنشفى.

9-تأمين ضعيف للمخازن المحمية للمواد الاشعاعية والكيمياوية، حيث تقع المخازن ثرب الوحدة الهندية وضمن الاقسام وتمتاز

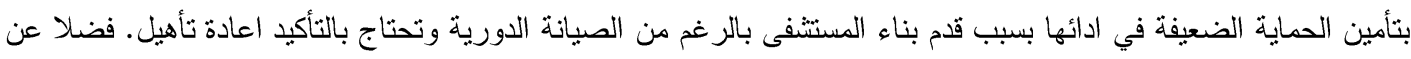

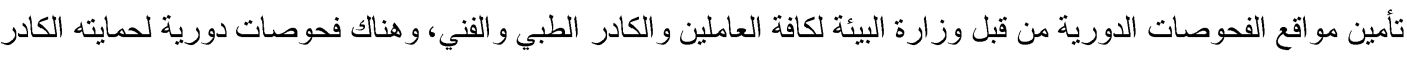
العاملين و المر افقين من نسبة الاثعاع إذا ما تجاوز النسبة المسموح بها في التعرض لكن الفحوصات الدورية نكثف انف ان هناك

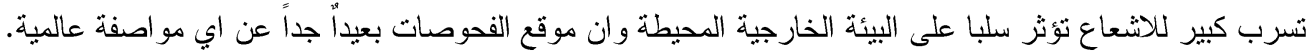

10-بالر غم من ان الثعبة الهندسية والصيانة تعمل ما بوسعها على توفير الصيانة الدورية بالحلول المتاحة لأفسام المستشفى، وبالر غم

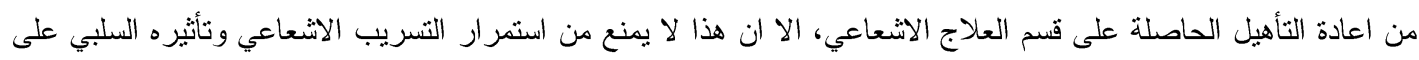

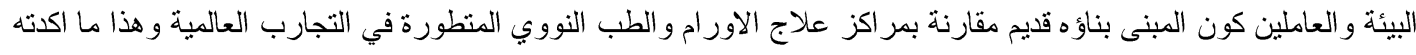
المقابلات الثخصية للباحث مع معظم المختصين من الملالك الطبي و الفني و الهندسي.

\section{8-الاستنتاجات العامة ولمستشفيات امراض الدم والاورام استناداً الى التجارب العالمية:} 1-يفضل تعدد الطرق الموصلة للمستثفى وذلك لتجنب الازدحام و لا سيما لسيار ات الاسعاف. 2- ان يكون الموقع قريبا من الخدمات العامة الاساسية مثل خطوط الكهرباءو الهاتق و الصرف الصحي 3-أن يكون الموقع المنتقى نظيفا بعيدا عن مناطق الضباب و التلوث و الروائح الكريهة وبعيدا عن الضوضاء. 4-أن يكون الموقع على اتصال بشبكات الطرق الرئيسة ومحطات المو اصلات العامة التي تعمل داخل نطاق المسنتفى. 5-توجيه مبنى المستثفى يتحكم به كلا من الطاقة الثمسية الحرارية و الضوئية فضلا عن الرياح في توجيه المستثفى، فيوجه مبنى المستتفى باتجاه الرياح السائدة وذات الأثر الجيد، في حين يكون المبنى موازيا للرياح غير مرغوب فيها وليها و بموازاة مع اهمية استغلال الطاقة الثمسية الحرارية في الموسم الثتوي و الطاقة الضوئية الطبيعية.

6-اختيار الابعاد المناسبة للفضاءات داخل اقسام المستثفى، حيث يكون التصميم واضحاً و مباشر اً في التعرف على الاقسام و سهولة الوصول اليها ولا سيما في مستشفى الاور ام حيث يساعد المرضى و مر افقيهم من الوصول الى الاقسام العلاجية المتعددة. 
7-تحقيق العلاقة الواضحة والخالية من التعقيد بين اقسام المستشفى بشكل عام، وبين فضاءات القسم الواحد، حيث يجب تجميع الفضاءات بطريقة نتتاسب ودرجة التقارب المكاني بين الفضاءات والاقسام، بحيث بحقق التقارب بين الفضاءات المرتبطة مع

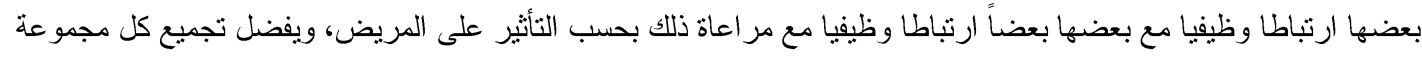

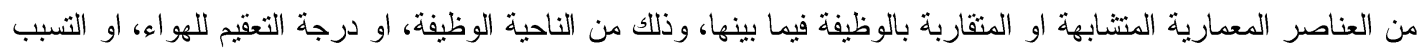

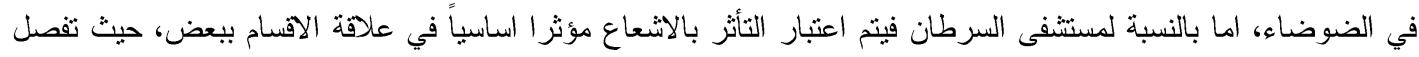

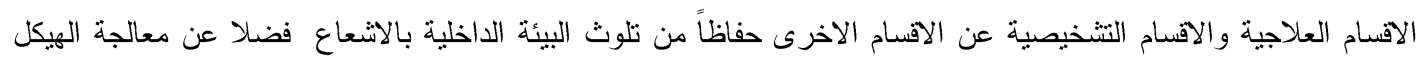
الخارجي العام للمستثفى من مؤثرات البيئة الطبيعيةو احتمالات ظهور الصو اعق الرعدية والصوام اعق وتأثير المرسلات الخارجية و التي ممكن ان تؤثر بشدة على فاعلية اجزةة العلاج والتشخيص. مورس

8- ينطلب ضمان التصميم الو اضح والسهل لممر ات الحركة، حيث تتناسب ابعادها مع انو اع الاستخدام الداخلي، مع التمبيز بين انواع

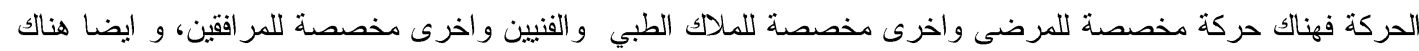

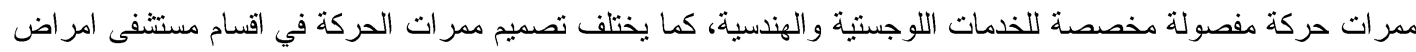

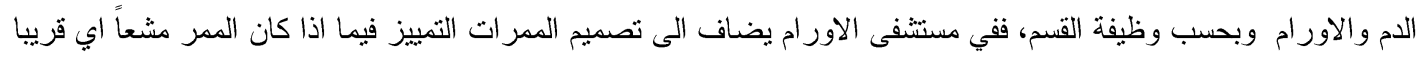
من اجزة العلاج فيجب غلقه بأبوب من الزجاج المرصص، مع الاخذ بالحسبان ضوابط تصميمه بحيث لا يؤثر على اقسام المستشفى الاخرى.

9-تحقيق خصوصية الاقسام بعضها من بعض وكذلك تحقيق خصوصية الفضاءات داخل الاقسام، حيث هنالك فضاءات لا يسمح للمريض بالوصول البها كغرف معدات الجهاز المشع، او هناك فضاءات يسمح ببعض المرضى استعمالها مثل الحمامات الخاصة بالمرضى المزروقين كبسولة اليود المشع، فضلا عن تحقيق الخصوصية في الاجنحة التمريضية والاقسام الاخرى.

10- يتأثر مركز امر اض الدم و الاور ام بالمتغيرات البيئية الداخلية والخارجية، خاصة اقسام التتخيص والعلاج فيها فهي تتأثر

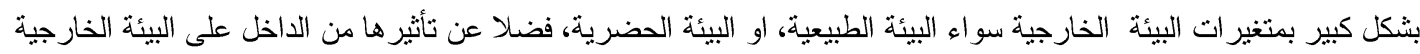
عن طريق الفضلات المشعة والاشعاعات المنبعثة من اقسام التشخيص والعلاج نحو الخارج او انتشار ها الخطر على كافة اقسامها الداخلية الاخرى، فضلا عن احتمالات تلوث الملاك الطبي و الفني والعاملين والمرضى والمر افقين، فيتم اتباع عدة طرق لنوفير الحماية من الجانبين لضمان عمل المركز بشكل دقيق وغير ملوث. 11- ان هدف مر اكز امر اض الدم والاور ام هو الارتقاء بصحة وحماية الفرد والمجتمع وذلك عن طريق توفير اجود مواصفات البيئة المريحة وضمان حماية كافة اقسام المركز الداخلية، وجميع أطر اف العملية العلاجية (الملاك الطبي، و الفني، و المرضى، و والمر افقين للمرضى، و العاملين)، وكذلك يتوجب استكمال جميع مدخلات البيئة العمر انية المطلوبة التي تحفز ضمان مخرجات جميع الاطر اف.

\section{CONFLICT OF INTERESTS.}

- There are no conflicts of interest.

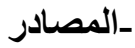

[1] Britannica, "Hospitals design", 20 September 2000, [Online]. Available: https://www.britannica.com/. [Accessed: oct. 20, 2018].

[2] فاطمة علي عبد الله، "النمط التصميمي المعاصر لأبنية المستثفيات التخصصية "، اطروحة دكتور اه، جامعة بغداد ،

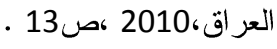

[3] .B. Rostenberg ،"The Architecture Of Medical Imaging", New York, 2006,pp.60.

[4] مجلس السرطان العر اقي ، "مر اكز السرطان في العراق،" بغداد،العراق، 2016، ص12.

[5] وزارة الثؤون السعودية، "دليل المعايير التخطبطية للخدمات،"الرياض، 2005،ص20 ـ

[6] سلسم احمد سليم، "التخطيط المكاني للخدمات الصحية"، اطروحة ماجسنير غير منشورة ، جامعة القس ، فلسطين، 
[7] J. Jaipur ‘" Hospital Planning and Designing " ‘India ،2013 ‘pp.30-35.

[8] Arch daily," Livsrum - Cancer Counseling Center / EFFEKT" ,Jan.8, 2014, [Online]. Available. https://www.archdaily.com/ 464296/livsrum-cancer [Accessed: Sept. 12, 2018].

[9] Arch daily Ballarat Regional Integrated Cancer Centre / Billard Leece Partnership, 26 September, 2013, [Online]. Available: https://www. archdaily.com/ ballarat-regionalintegrated-cancer-centre-billard-leece-partnership. [Accessed: oct. 12, 2018].

[10] R. Sprow," Planning Hospitals", U.S.A, Quercus Publishing Inc, 2012,pp.25.

[11] Prof. Dr. Annette Grüters-Kieslich,"Tumor hospitals design", Aug. 18 ,2017, [Online], Available: https://www.heidelberg-university-hospital.com/ diseases-treatment. [Accessed: oct. $12,2018]$.

[12] Who,"Hospitals Guidelines for Development" Princeton Architectural pp. 57-56.، 1996 ، Press, New York

[13] . J . Malkin ، Medical And Dental Space Planning ‘2002, pp.54.

[14] R. Kudchadker," Radiation vault design and shielding", ”, Ph.D. thesis, Univ. of Cambridge, Uk, 2013,pp.160.

[15] B. Rostenberg, "Improving medical care Environments", Hong Kong, China, Konemann, 2013, pp.52-55.

[16] ."International Health Facility Guidelines " ، USA,2016 , pp.60.

[17] Oxford, Butterworth-Heinemann, 2010, pp.29.6 " ICRC,"medical waste .

[18] "International Health Facility "‘New Yourk ‘2016 Quercus Publishing Inc‘pp.110.

[19] .Veterans Affiars ," Nuclear Medicine Design Guide" German ‘2008‘pp.15-14

[20] رشاد شبيب،" التصوير الطبي-الموسوعة العربية " دار دمشق للطباعة، سوريا، 2009 ، ص89. 